In: Why birds matter: Avian Ecological Function and Ecosystem Services. Eds. C.H. Şekercioğlu, D.G. Wenny, C.J. Whelan. University of Chicago Press. ISBN: 9780226382630

\title{
Dispersal of Plants by Waterbirds
}

Andy J. Green, Merel Soons, Anne-Laure Brochet, and Erik Kleyheeg

The widespread distribution of fresh-water plants and of the lower animals, whether retaining the same identical form or in some degree modified, I believe mainly depends on the wide dispersal of their seeds and eggs by animals, more especially by fresh-water birds, which have large powers of flight, and naturally travel from one to another and often distant piece of water. —Charles Darwin ( 1859 )

$\mathrm{H}$ umans have had a long and special relationship with waterbirds, particularly as sources of food both in the wild and following domestication (Kear I990; Green and Elmberg 20I4). Today waterbirds remain a great attraction as hunting quarry, and tens of millions of dollars are spent each year by waterfowl hunters in North America alone. Bird watchers and other people visiting nature reservess often search out the major spectacle provided by waterbirds on migration or on their wintering grounds. Management for hunting or conservation interests often focuses on the measures that attract the largest concentrations or diversity of migratory waterbirds. However, managers usually pay little or no attention to the vital role of birds as dispersers of plants and invertebrates that lack their own active means of dispersal, but which can be transported over great distances on the outside or inside of waterbirds.

The dispersal of viable plant units (hereafter "diaspores") may be the most important ecosystem service provided by birds (Şekercioğlu 2006). However, the great majority of diaspore dispersal literature focuses on the dispersal of plants with fleshy fruits by terrestrial birds (chapter 5). Nevertheless, ducks, shorebirds, and other waterbirds play major roles as vectors of passive dispersal for plants, both by internal transport within their guts ("endozoochory"; e.g., see Figuerola and Green 2002a; van Leeuwen 


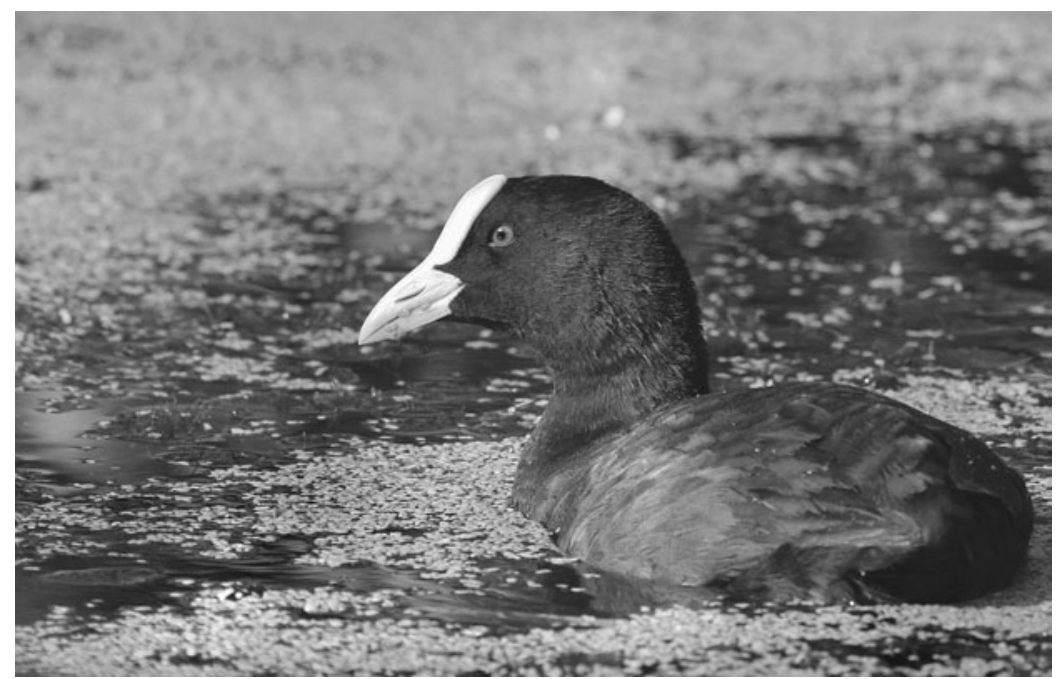

FIGURE 6.I. Eurasian coot (Fulica atra) with duckweed (Lemna gibba or L. minor) attached to its bill. Photo by Nicky Petkov / www.NaturePhotos.eu.

et al. 2012) and by external transport on feathers or skin ("epizoochory" or "ectozoochory"; e.g., see Figuerola and Green 2002b; Brochet et al. 20 I0a; fig. 6.I). As shown experimentally by Darwin (i859), secondary internal transport can also occur, when diaspores are first ingested by fish or crustaceans that are then predated by piscivorous birds. In addition, plants may be dispersed when waterbirds use them as nest material. Many of the plants dispersed by waterbirds are major components of ecosystems, and provide numerous indirect benefits to humans.

Dispersal is crucial for the regional survival, range expansion, and migration of plant species, especially plants that are confined to spatially discrete habitats in an otherwise unsuitable landscape (Howe and Smallwood I982). Nonmarine aquatic or wetland habitats are often islandlike in their spatial isolation from one another. Dispersal processes to islands and to inland waterbodies, such as lakes or ponds, are cases in which metapopulation or metacommunity models apply to plant populations (whether island, or aquatic, or both). In both island and island-like aquatic systems, waterbirds are important vectors of passive dispersal for numerous plant species. They are highly mobile on short and long timescales, including frequent daily movements and seasonal long-distance migrations. They are thus particularly good vectors for long-distance dispersal and maintain connectivity between plant populations in different catchments that 
have no active means of interchange (Amezaga et al. 2002). Their importance as vectors is even greater today, as plants and other organisms need to move to adapt to the rapid changes to natural environments caused by human activity, including climate change. Suitable habitats for plant species change distribution continuously (e.g. as temporary wetlands dry and reflood, as some wetlands are degraded whilst others are created, or as the distribution of the suitable temperature range changes), and waterbirds provide a means by which plant species can track these changes.

Although waterbirds sometimes feed on fleshy fruits and disperse the seeds within, they mainly disperse wetland and terrestrial plants that lack fleshy fruits. Most plant species have what van der Pijl (1972) called "nonadapted diaspores" because they lack a fleshy-fruit and a priori are not obviously adapted for internal transport, while at the same time lacking hooks, barbs, or other apparent adaptations for external transport. Plant families lacking fleshy fruits have often been wrongly assumed to be exclusively dispersed by abiotic means such as wind or water, and for that reason many reviews of "zoochory" or biotic dispersal make no mention of waterbirds as vectors of diaspores (e.g. Tiffney 2004). Like interactions between herbaceous diaspores and large mammals (Janzen I984), the study of interactions between plants and waterbirds has been rather unfashionable compared with interactions between vertebrates and forest plants with fleshy fruits. This is ironic, since Darwin ( 1859 ) paid more attention to the role of waterbirds as dispersal vectors than to the role of frugivores.

Diaspore dispersal by waterbirds is an ancient process that likely dates to the origin of waterbirds in the Early Cretaceous, coinciding with the origin and early radiation of the angiosperms (Soltis et al. 2008; Lockley et al. 20I2). Darwin ( I859) first drew attention to diaspore dispersal by waterbirds. He realized that their capacity as vectors of passive dispersal, coupled with their frequent and long-distance movements, provided an explanation over evolutionary timescales for the widespread distributions of many aquatic organisms, despite their own limitations for movement. Most of the literature exploring the dispersal of diaspores by waterbirds in detail focuses on aquatic plants. The truly aquatic plants (e.g., pondweeds) have no capacity for wind dispersal (anemochory, van der Pijl I972), and this increases their dependency on dispersal by animals (zoochory) and water (hydrochory). However, dispersal by water is always limited to areas connected by surface water flows and thus cannot result in dispersal to isolated water bodies or wetlands in different catchments. Waterbirds also disperse diaspores of a variety of terrestrial plants, especially those from moist soils and those whose diaspores end up 
being washed or blown into wetlands. The boundaries between "aquatic" and "terrestrial" are not rigid or clear-cut, since many important habitats are dynamic and are inundated only for part of the time and most waterbirds are not entirely aquatic. Furthermore, some aquatic plants can often tolerate a short terrestrial phase, and vice versa. Dormant diaspores can remain in seed banks until favorable conditions (whether wetter or drier) arise. Diaspore dispersal by waterbirds may be relatively unimportant in closed forests, but forests cover only $3 \mathrm{I} \%$ of total land area (http:// www.fao.org/forestry/28808/en/). Furthermore, forest streams are often frequented by herons, kingfishers or specialized ducks, all of which may have an important role as vectors of dispersal upstream or between catchments. Wetlands cover an estimated I $2 \%$ of land area (Downing 2009), but their catchment areas are far more extensive.

This chapter focuses on current understanding of plant dispersal by waterbirds. We begin with a review of principal waterbird families and their importance as plant vectors. We then review current understanding of the importance of zoochory for the ecology of plants, effects on seeds of gut passage through the waterbird gut, the plants that are dispersed, and the extent to which seed morphology can predict waterbird dispersal. We next consider the coupling of seed dispersal with seed production, the role of plant-waterbird coevolution, and the seed adaptations that exist for waterbird dispersal. We then focus on establishment success of dispersed diaspores. We conclude by considering how all this dispersal provides benefits to humans.

\section{Waterbirds That Are Diaspore Vectors}

No systematic surveys compare the relative importance of all waterbirds in a given region as vectors, and this makes generalizations about the roles of different bird groups difficult. All species can be expected to have some role in external and internal diaspore dispersal. Many waterbirds are dietary generalists. Many species of herons, spoonbills, cormorants, grebes, or terns concentrate on fish, although most of these birds also eat amphibians, reptiles, and large invertebrates such as crayfish. These waterbirds have major potential for secondary dispersal of plant diaspores ingested by their prey. Other waterbirds, such as storks, ibis, ducks, rails, gulls, and shorebirds, are typically omnivorous, eating a range of animals and plant material and varying their diets with age, season, or geographic location. Some birds, such as geese, wigeon, swans, and rallids (e.g. coots or 
swamphens), are largely herbivorous but also ingest and disperse diaspores. The same is true of shorebirds and flamingos, which are often assumed to be invertebrate predators.

Factors determining the importance of different waterbird species as vectors include their abundance and degree of migratory behavior, both of which are relatively well studied. In terms of numbers of species, populations and individuals, the Anatidae, shorebirds, Rallidae, and Laridae (gulls and terns) are the most important waterbird groups, followed by Ardeidae (herons and egrets; Wetlands International 20I2; see fig. 6.2), and each of these groups is considered separately below.

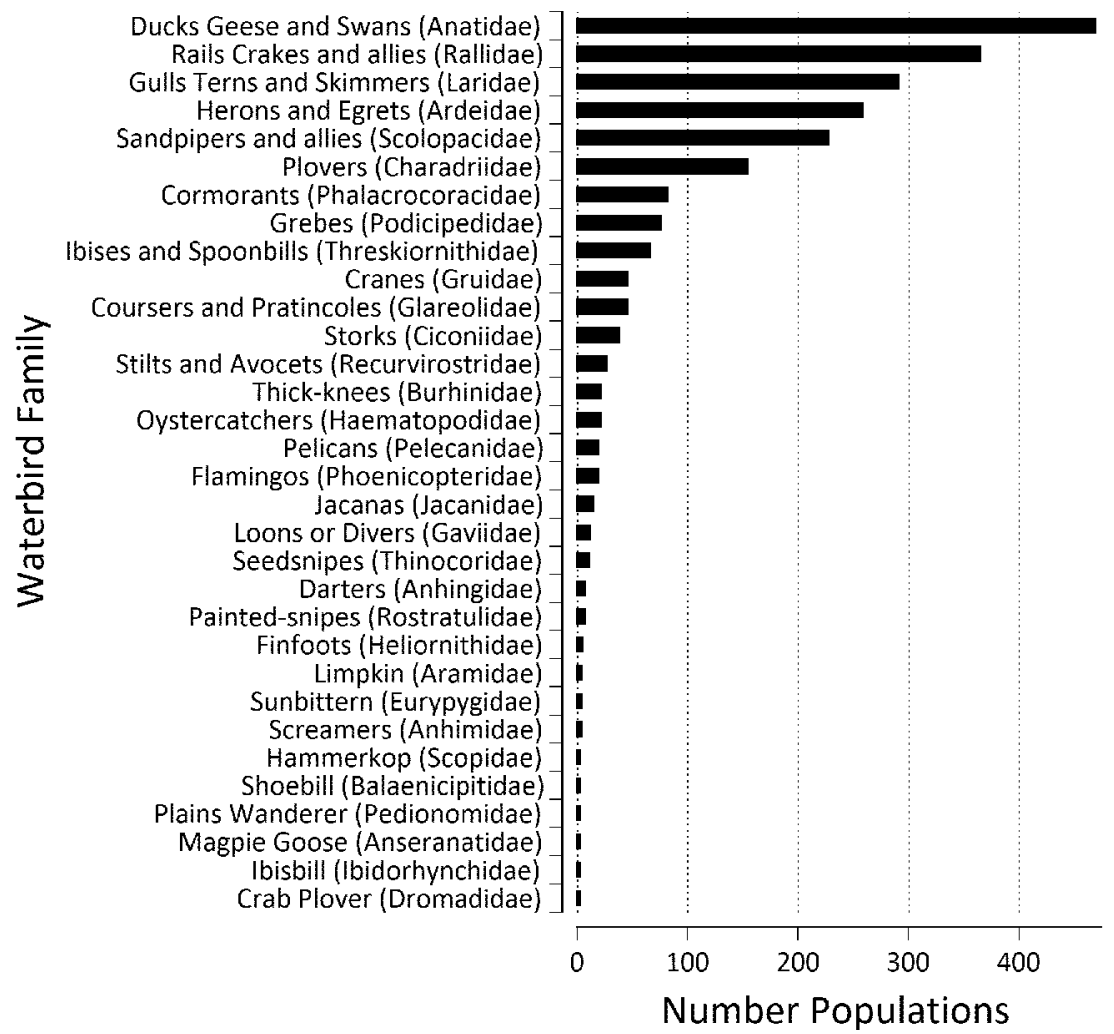

FIGURE 6.2. Overview of bird families included in the term "waterbirds" as applied in this chapter, with the global number of waterbird populations per family (from Wetlands International 20I2; details of population size for each population are available online at wpe.wet lands.org). 


\section{Anatidae}

Ridley (I930) provided extensive lists of plants whose seeds have been found in the guts of many waterfowl, especially Holarctic ducks. He found Cyperaceae particularly dependent on dispersal by ducks, and this is supported by recent literature. Migratory Anatidae are tremendously important diaspore dispersers in the Northern Hemisphere. Continental North America alone supports an estimated 49 million ducks, more than Io million geese, and around 200,000 swans (USFWS 2012).

Pioneering research by Proctor and coworkers (Proctor I968; deVlaming and Proctor I968) has stimulated detailed, systematic, and quantitative studies on seed dispersal by waterbirds, but the great majority have focused on Anas ducks, for several reasons. First, Anas species are widespread and abundant, rendering them obvious candidates for study. Second, their ecology is well known, owing largely to their importance as hunting quarry, and diet studies have long since established that Anas species feed, often to a large extent, on plant seeds. Third, they are easily kept in captivity and legally hunted in large numbers, making them readily available as study objects both pre- and postmortem. For these reasons, most of the examples and analyses further on in this chapter are based on Holarctic Anas ducks. Hence, in this section we concentrate on the literature on other Anatidae species.

Investigations of the Pacific black duck (Anas superciliosa), grey teal (Anas gracilis), and chestnut teal (Anas castanea; Green et al. 2008; Raulings et al. 20I I) of Australia confirm that both nomadic and seasonal migrant ducks are important endo- and epizoochorous seed vectors. In the Mediterranean region, the nomadic and globally threatened marbled teal (Marmaronetta angustirostris; subfamily Aythyinae) is also an important vector (Green et al. 2002; Fuentes et al. 2005). Amongst fish-eating migrants from the Merginae subfamily, red-breasted mergansers (Mergus serrator) and buffleheads (Bucephala albeola) were shown to carry seeds externally in New Jersey (Vivian-Smith and Stiles I994).

The true geese (subfamily Anserinae) are more terrestrial than ducks, and in some cases are important for dispersal of plants with fleshy fruits. The endemic and globally threatened Hawaiian goose (Branta sandvicensis) disperses berries such as Coprosma erno-deoides (Rubiaceae), Vaccinium reticulatum, Styphelia tameiameiae (Ericaceae), and the Chilean strawberry (Fragaria chilensis; Rosaceae), as well as seeds of the alien sow thistle (Sonchus asper [Asteraceae]; Guppy I906). Black et al. (I994) analyzed the feces of this goose and found four kinds of berries (mainly 
S. tamaiameiae and $V$. reticulatum) and five types of grass seeds, especially molasses grass (Melinis minutiflora). Ridley (1930) reported how snow geese (Anser hyperboreus) consumed Empetrum nigrum (Ericaceae) berries and Potamogeton natans seeds, and greylag geese (Anser anser) consumed Rubus chamaemorus (Rosaceae) berries.

Geese grazing on grasses and other green plant material often ingest diaspores and disperse them in their feces in a manner analogous to that of herbivorous mammals which ingest seeds along with foliage (Janzen I984). Barnacle geese (Branta leucopsis) are important for endozoochory in Arctic tundra (Bruun et al. 2008) and the Netherlands (Chang et al. 2005), while Canada geese (B. canadensis) are vectors of a range of native plants (Morton and Hogg I989; Neff and Baldwin 2005) and alien grasses (IsaacRenton et al. 2010). Viable seeds of Scirpus maritimus, S. litoralis (in Spain: A. J. Green and J. Figuerola, unpublished) have been recorded in the feces of migratory greylags. Seeds of smooth cordgrass (Spartina alterniflora), seashore saltgrass (Distichlis spicata), and seven other species were found on feet and feathers of brant geese (Branta bernicla) in New Jersey (VivianSmith and Stiles I994). Brant geese in Europe feed on Salicornia europaea seeds (Summers et al. I993).

Relatively little is known about diaspore dispersal by true swans (subfamily Anserinae), which may be more important vectors of aquatic plants than geese. Ridley (I930) reported that both mute swans (Cygnus olor) and Bewick's swan (C. columbianus) consumed P. natans seeds. Feces from black swans (Cygnus atratus) in Australia contained viable seeds of Typha and alien Medicago and Polygonum (Green et al. 2008).

Other groups of Anatidae are likely important diaspore vectors. Ridley (I930) proposed that whistling ducks (Dendrocygninae) are good vectors, as they ingest many aquatic plant species and range widely in areas like the Caribbean and Indonesia. The high proportion and variety of seeds in the diet of African and Australian Dendrocygna (Green et al. 2002) supports this. In South Africa, the spur-winged goose (Plectropterus gambensis [Plectropterinae]) ingests a variety of seeds (Halse I985). The aberrant magpie goose (Anseranas semipalmata; often placed in its own family, the Anseranatidae) feeds partly on grass, Polygonum, and other seeds (Marchant and Higgins I990).

Within the Tadorninae (shelduck subfamily), Ridley (I930) reported that the upland goose (Chloephaga picta) consumed berries of Empetrum rubrum in the Falkland Islands. In Tierra del Fuego, this species and the ashy-headed goose (C. poliocephala) are important frugivores (Willson et al. 1997). The shelduck (Tadorna tadorna) is a likely vector for Salicornia 
seeds (Viain et al. 20I I). In South Africa, the Egyptian goose (Alopochen aegyptiacus) is likely to be an important seed vector (Halse I984). Fossilized feces of the extinct, flightless Thambetochen chauliodous from Hawaii, the size of a large swan but more related to shelducks or dabbling ducks, were rich in fern spores (James \& Burney I997).

\section{Rallidae}

Eurasian coot (Fulica atra; fig. 6.I) are similar to sympatric ducks in their internal dispersal of diaspores, with Chara in feces in France (Charalambidou and Santamaria 2005), viable Ruppia and Arthrocnemum seeds in Spain (Figuerola et al. 2002, 2003), and viable Typha seeds in Australia (Green et al. 2008). Diaspores of at least I3 species were present in their upper gut in northeast France (Mouronval et al. 2007), and I3 species in the Camargue, where coot consumed more seeds than gadwall (Anas strepera; A1louche and Tamisier I984). Various saltmarsh seeds have been recorded on the feet and plumage of coot in Spain (Figuerola and Green 2002b), and Cook (I990) proposed that the seeds of the water lily (Nymphoides peltata) are dispersed when stuck on the bill or shield of coot.

Common gallinules (Gallinula galeata) in Argentina consumed seeds throughout the annual cycle, especially Polygonaceae and Poaceae (Beltzer et al. I99I). Sticky seeds of Pisonia grandis were recorded attached to six common moorhens (Gallinula chloropus) in the Seychelles, as well as to several seabird species (Burger 2005). Ridley (I930) reported that the water rail (Rallus aquaticus) takes Rosa and grass seeds, while the buff-banded rail (Hypotaenidia philippensis) eats fruits of Freycinetia banskii in New Zealand. Rails of the genus Porphyrio are major vectors of the genus Coprosma (Rubiaceae) within and between New Zealand and Pacific islands, and Scleria seeds (Cyperaceae) were in the gut of Porphyrio in Fiji (Guppy I906). A seed of the Japanese chaff flower (Achyranthes japonica) was found in the feathers of a Swinhoe's rail (Coturnicops exquisitus; Choi et al. 20I0). Seeds, especially Caperonia palustris (Euphorbiacea), Thalia geniculata (Marantaceae), Eleocharis (Cyperaceae), Ludwigia (Onagraceae) and Neptunia oleraceae (Fabaceae), are major food items of the purple gallinule (Porphyrio martinincus) in Venezuela (Tárano et al. I995). Viable seeds of four Eleocharis species were recovered from feces of purple swamphen (P. porphyrio) in Australia (Bell 200o). Seeds of Typhaceae (Sparganium ramosum) and Cyperaceae (Scirpus spp. and Carex divisa) are a major part of the diet of this species in Spain (Rodríguez and Hiraldo I975). 


\section{Shorebirds}

The shorebirds (or "waders" as they are often called in Europe, not to be confused with "wading birds" in the North American sense) are a group of waterbird families with a similar morphology and ecology, within the order Charadriiformes. With migrations often across seas and oceans, their potential importance in diaspore dispersal to oceanic islands has long been recognized. Ridley (1930) reported internal transport of berry seeds by shorebirds, referring to the consumption of Vaccinium and Empetrum berries by Eurasian curlew (Numenius arquata) and Pluvialis plovers, and of Canthium fruits by bristle-thighed curlew (N. tahitensis) in Pacific islands. De Vlaming and Proctor (1968) were the first to demonstrate that Charadriidae shorebirds disperse angiosperms lacking fleshy fruits by internal transport. Proctor (1968) found experimentally that viable seeds that were regurgitated after being retained in the shorebird gizzard for up to 340 hours in killdeer (Charadrius vociferus) and 216 hours in least sandpiper (Calidris minutilla) remain viable. Proctor (1968) also observed that shorebirds reingest seeds regurgitated by individuals of other species. A given seed may thus be transferred between species and dispersed to and from microhabitats used by different species (e.g., terrestrial habitats). This seed transfer among different species may facilitate effective longdistance dispersal of diaspores. The extraordinary nonstop flights of bartailed godwits (Limosa lapponica) of over 8,00o km across the Pacific (Gill et al. 2009) underline their potential for long-distance dispersal.

Most shorebirds include seeds in their diet, including 37 of 55 shorebird species in the Western Palaearctic and 26 of 35 species in North America (Green et al. 2002). Seeds of at least I22 genera from 48 families have been recorded in the guts of common snipe (Gallinago gallinago; Mueller 1999). Seeds can be the most important food item for various species at certain times of the year, even at stoppage sites during spring and autumn migration (Green et al. 2002). On wintering grounds in Argentina, seeds from at least eight plant families were the only food items recorded for white-rumped sandpiper (Calidris fuscicollis; Montalti et al. 2003). External transport by shorebirds is also important but largely unstudied. Darwin (I872) germinated a seed of toad rush (Juncus bufonius) removed from mud attached to the leg of a Eurasian woodcock, Scolopax rusticola. Bryophyte and algal diaspores were recovered from the plumage of American goldenplover (Pluvialis dominica), semipalmated sandipiper (Calidris pusilla), and red phalarope (Phalaropus fulicarius; Lewis et al. 2014). 
Sánchez et al. (2006) examined seed viability following passage through shorebird guts in the field. Viable seeds of Mesembryanthemum nodiflorum (Aizoaceae), Sonchus oleraceus (Asteraceae) and Arthrocnemum macrostachyum (Chenopodiaceae) were frequent in pellets and feces of common redshank, spotted redshank (Tringa erythropus), and black-tailed godwit (Limosa limosa) during spring and autumn migrations in Spain (Sánchez et al. 2006). Another I I seed types were recorded at low densities.

\section{Gulls}

Calvino-Cancela (20 I I) reviewed internal transport by gulls. Berries are a major part of the diet of many species, and dispersal of fleshy-fruited plants by gulls greatly influences the development of oceanic island plant communities. However, seeds of plants lacking a fleshy fruit, common in grasslands and cultivated fields, are also dispersed. Seeds have been recorded in the diet of at least 22 gull species, mainly those using inland freshwater habitats. Gulls are not efficient at digesting seeds, and often regurgitate or defecate them intact. Plants dispersed include many genera frequent in duck diets, such as Polygonum, Plantago, Chenopodium, Rumex, Carex and Scirpus. Retention times can exceed 70 hours for defecated seeds and 45 hours for regurgitated seeds, and viability has been demonstrated in several studies. On Surtsey, a volcanic island that appeared in I963, gulls have brought most of the soil nitrogen, as well as most of the plants (Magnússon et al. 2009).

Gulls help spread alien weeds from agricultural land and garbage dumps to islands. Morton and Hogg (I989) recovered seeds of 23 plant species in pellets and feces of ring-billed gull (Larus delawarensis) and herring gull (L. argentatus) on an island in Lake Huron. Seeds of nineteen species later germinated. Most (I8) of these plant species were exotics (e.g., Poa annua, Chenopodium album, Amaranthus retroflexus and Taraxacum officinale) that dominated vegetation around the nesting sites. They also found that herring gull nests contained I5 plant species (only two of which were present in pellets and feces) with viable rootstocks, rhizomes, or seeds.

Earthworms, which themselves ingest and disperse diaspores (Milcu et al. 2006), are common in gull diets (Calvino-Cancela 20 I I). Gulls may indirectly disperse diaspores within the earthworms they consume.

\section{Herons}

Grey heron (Ardea cinerea) pellets in Tenerife contained seeds of at least I6 plant species ingested by lizards which are preyed on by the herons, 
facilitating secondary dispersal of terrestrial plants, although to a lesser extent than by kestrels and shrikes (Rodríguez et al. 2007). Heslop-Harrison ( I955) reported viable seeds of Nuphar lutea (presumed to have been eaten by a fish) in excreta from a grey heron. Corlett (I998) reported that cattle egrets (Bubulcus ibis) eat figs. Seeds of Achyranthes japonica were found in the feathers of a Eurasian bittern (Botaurus stellaris; Choi et al. 20Io).

\section{Other Waterbirds}

Arber (I920) reported that Weddell (I849; predating Darwin I859) observed a tiny, previously unknown floating plant on the feathers of a waterbird in Brazil (a "camichi," a local name for a horned screamer [Palamedea cornuta], according to Maximilian I820). Weddell described this new species as Wolffia brasiliensis. Greater flamingos (Phoenicopterus roseus) often filter food items from the sediments, and ingest Ruppia maritima seeds (Rodríguez-Pérez and Green 2006) and presumably many other diaspores. Holmboe (I900) reported that common cranes (Grus grus) consumed Vaccinium vitis-idea berries. Australian pelican (Pelecanus conspicillatus) feces contained viable diaspores of Lemna, Nitella and Typha, which were presumably first ingested by fish (Green et al. 2008). Ridley (I930) reported occasional seeds in the stomachs of grebes.

Ridley (I930) reported the presence of berries in the diets of skuas, and occasional seeds in petrels. Aoyama et al. (20I2) quantified external transport of nine plant species by four species of seabird: the black-footed albatross (Phoebastria nigripes), Bulwer's petrel (Bulweria bulwerii), wedge-tailed shearwater (Puffinus pacificus), and brown booby (Sula leucogaster). Carlquist ( 1967) observed sticky Boerhavia diffusa fruits on the feathers of the sooty tern (Onychoprion fuscatus). Taylor (I954) and Falla ( I960) suggested that various plants reached oceanic islands through external transport on albatrosses and petrels.

\section{The Significance of Passive Dispersal by Waterbirds for Wetland Plant Species}

Wetlands often occur spatially scattered throughout otherwise dry (or drier) terrestrial landscapes, so that wetland habitat exists in the form of discrete and isolated patches in an otherwise unsuitable landscape. Human land development has reduced wetland area and increased wetland fragmentation globally, exacerbating the isolation of remaining wetland areas 
(Davidson 2014). Loss of connectivity between isolated wetlands and associated changes in land use may result in local and regional species extinctions, loss of regional species dynamics, and increased vulnerability of remnant populations to stresses such as pollution or climate change (Amezaga et al. 2002; Lougheed et al. 2008; Wormworth and Şekercioğlu 20I I). Even under natural conditions, plant species must disperse across the landscape to reach new wetland habitats in order to escape from predators, pests, and pathogens and to reach new unoccupied sites to balance the loss of occupied sites. Hence, for the preservation of wetland plant diversity and wetland functions provided by the plant species, dispersal among wetlands is crucial.

Five main dispersal mechanisms have the potential to connect isolated wetlands: wind, water, birds, humans, and other animals. Dispersal by wind is uncommon in submerged or floating plants, as they mostly produce diaspores under or in the water. Many plants (most notably the tall Epilobium, Typha, and Phragmites species and trees such as Salix, Alnus, and Betula) produce seeds in and around wetlands that are well dispersed by wind over distances exceeding tens of kilometers, but the direction of the wind is unpredictable and many seeds are lost (Soons 2006). Hydrochory of diaspores produced under, in, or near the water surface transports diaspores between wet areas likely to offer suitable habitat (Sarneel et al. 20I3; Soomers et al. 20I3). However, water flows transport diaspores only downstream and between hydrologically connected wetlands (Soons 2006). Animals in search of water may provide a much more targeted (or "directed") means of dispersal among all wetland types, which is essential to maintain the viability of wetland plant populations (Purves and Dushoff 2005; Kleyheeg 2015).

Both mammals and birds are able to transport large numbers of plant diaspores over long distances, but large migratory mammals have been subjected to massive prehistorical extinctions (Janzen I984), and nowadays are restricted by movement barriers such as fences and inhabited areas, which birds can easily surpass. Given the abundance of waterbirds, their role in the directed dispersal of diaspores among wetlands is critical.

Although aquatic plants disperse via asexual propagules such as rhizomes or stem fragments, these propagules are typically more important for dispersal within a catchment by hydrochory (Santamaria 2002), or for short-distance dispersal by external transport. Dispersal among catchments is predominantly by internal or external transport of seeds. Although small floating plants such as Lemna or Azolla may be exceptions (fig. 6.I), they have limited resistance to desiccation during external transport (Coughlan et al. 2015). 
Despite major advances in taxonomy and the discovery of cryptic species using molecular methods, Darwin's (1859) observation that aquatic plants have particularly broad distributions has stood the test of time. Aquatic plants have lower levels of endemism, and are more likely than terrestrial plants to occur on more than one continent. Within a genus such as Ranunculus, which has many European species, aquatic species have a greater latitudinal range and overall area of occupancy than do terrestrial species (Santamaria 2002). The biogeography of aquatic plants thus shows a lasting footprint of long-distance dispersal. Corresponding to their high dispersal ability, natural selection has honed aquatic plants with general purpose genotypes, high stress tolerance and high clonal persistence, all of which allows them to occupy large ranges.

The importance of seed dispersal for aquatic plants varies with the spatial configuration of wetlands in the landscape across fragmentation gradients which include latitudinal and climatic gradients. In Europe, the proportion of temporary aquatic habitats increases from north to southand with it, the relative importance of sexual reproduction. In northern habitats, plants are more able to spread within a habitat and to persist from year to year in the absence of seed production (often overwintering as rhizomes). The chances of seedling establishment can be extremely low, owing to intense competition with established plants (Santamaria 2002). Hence, seeds of aquatic plants appear adapted for long-distance dispersal to unoccupied habitats rather than local dispersal within an already occupied habitat. In contrast, in the Mediterranean region of southern Europe, aquatic habitats are highly dynamic and often temporary, and suitable microhabitats for a given plant species often change greatly from one season or year to the next. Ponds and lakes often dry out completely in summer or during drought cycles. Hence, diaspores with dormant capacity (seeds or spores) are important at a local scale for survival of drought and for colonization of areas that become suitable in a given year. Seed dispersal within a wetland complex becomes more important, and may be more likely to be followed by successful establishment than in northern permanent habitats. Birds are also typically major seed dispersal vectors within a wetland complex, often moving the seeds to sites they could not reach by hydrochory (Figuerola et al. 2003; Brochet et al. 20I0a). These latitudinal patterns explain why widespread pondweed species, such as Potamogeton pectinatus, invest more in seed production in southern than in northern populations (Santamaria et al. 2005).

De Vlaming and Proctor ( I968) emphasized that because most aquatic plants are monoecious, a single viable diaspore dispersed to a new habitat 
may be sufficient to establish a new population. Similarly Cruden (I966) pointed out that most plants with a distribution suggesting long-distance dispersal by shorebirds are self-compatible. Proctor (I980) showed for the Characeae that only bisexual or parthenogenetic taxa are present on isolated oceanic islands. In contrast, dioecious taxa are restricted to continental land masses and islands within a maximum range of 200 to $300 \mathrm{~km}$, such that repeated dispersal events allow establishment of both sexes.

\section{What Happens to Diaspores in the Waterbird Gut?}

For almost all plant species whose seeds are ingested by ducks, some seeds survive gut transit (Brochet et al. 2009). Exceptions appear due to large seed size, which makes gut passage unlikely. Aquatic seeds that seldom survive passage through the waterbird gut include the large, soft seeds of the water lilies Nymphaea alba, Nuphar lutea, and Nymphoides peltata (Smits et al. I989; Soons et al. 2008), which are favored food items of ducks (Tréca I98I). However, the seeds of these species are adapted for external transport (Smits et al. I989; Cook I990). They may also be secondarily dispersed by internal transport when they are in fish ingested by piscivorous birds. Such large seeds may also be regurgitated by waterbirds occasionally without damage (Kleyheeg 20I5). During experiments, mallards sometimes regurgitate charophytes before they enter the gizzard (Malone I966).

In an experimental study in which seeds of 23 wetland plant species were fed to mallards, the proportion of seeds retrieved from feces varied from o to $54 \%$, with a negative relationship between seed volume and retrieval (Soons et al. 2008). In the same study, smaller seeds were retained for less time in the gut. In a similar study in which diaspores of eight species were fed to green-winged teal (Anas crecca), retrieval varied from 2 to $83 \%$ (Brochet et al. 20Iob). Wongsriphuek et al. (2008) found that seed retrieval increased with higher fiber content among Io wetland species fed to mallards. Retrieval was not related to seed size. Van Leeuwen et al. (20I2) found in a meta-analysis that larger propagules, including plant seeds, have lower survival during passage through the waterfowl gut; but GarcíaÁlvarez et al. (2015) showed that there are exceptions with large, durable seeds, such as the invasive primrose Ludwigia grandiflora (Onagraceae).

The fact that many seeds survive gut processing by waterbirds can be explained by optimality modeling (Sibly i98 I; van Leeuwen et al. 20I2). Even when ducks are consuming a single preferred seed species which provides 
a high assimilation rate, the diminishing returns from the digestion of the last fractions of seeds renders total digestion suboptimal. Since ducks are highly omnivorous, they may often consume and process a combination of different seed types with other plant or animal food, and retention time may be determined largely by the optimal strategy for digesting foods other than seeds.

Thus, Sibly's (I98I) model would predict that seeds mixed with higherquality food, such as animal pellets, should be retained for shorter periods than those mixed with lower-quality food such as plant leaves, as was observed with digestive markers by Charalambidou et al. (2005). Similarly, when food items are more available in the feeding environment and handling times are reduced, optimality theory predicts that gut passage rate can be increased, thus increasing the rate of diaspore survival. This expectation is supported by field studies, indicating that seed survival increases when ducks ingest seeds at a higher rate (Figuerola et al. 2002; Green et al. 2002).

Waterbirds are likely to select seeds partly on their nutritional quality, which is likely to be positively related to their digestibility and negatively related to their capacity to survive digestion. Thus, the breeding white-faced whistling duck (Dendrocygna viduata) and red-billed teal (Anas erythrorhyncha) fed largely on Panicum schinzii seeds, which had a particularly high fat content (Petrie I996; Petrie and Rogers I996). Given their bill morphology, it is difficult for ducks to reject relatively poor quality seeds mixed with other foods (Gurd 2006), and they typically ingest many kinds of seeds simultaneously (Brochet et al. 2012a). The digestive assimilation efficiency of seeds varies among bird species and even between sexes of a given waterbird species (Santiago-Quesada et al. 2009).

Variation in overall retention time between food items such as diaspores is partly related to variation in the time they are retained in the gizzard. Larger items tend to be retained longer, which explains why smaller seeds generally have shorter overall retention times (Soons et al. 2008; Kleyheeg 20I5; but see Figuerola et al. 20I0). Unlike frugivores, retention time in waterfowl is negatively related to body size, making smaller species better vectors (García-Álvarez et al. 2015).

The chance that a diaspore survives retention in the gizzard is related to the strength of the gizzard and to the amount of grit (small stones) present to crush food (Kleyheeg 2015). The size and quantity of grit varies between individuals and species of waterfowl in a manner related to diet, with herbivorous species having more grit (Figuerola et al. 2005a). Some 
authors have suggested that shorebirds sometimes ingest hard seeds for the same reason they ingest grit: to help crush other food in the gizzard, rather than for direct nutritional benefit (Green et al. 2002). It is difficult to mimic natural conditions in captivity, and existing studies of seed survival and retention times may be misleading. Wild ducks tend to have larger gizzards and intestines than do captive ones (Charalambidou and Santamaría 2002), such that captive studies may tend to overestimate seed survival while perhaps underestimating retention times. On the other hand, the low activity levels of captive birds compared to those of wild ones, which spend much time swimming or flying, may lead to a major underestimation of the proportion of seeds that survive gut passage, as well as a slight overestimation of retention times (Kleyheeg et al. 2015).

Recent studies addressed the effects of passage through the waterbird gut on germinability (the probability of germination) and germination rate (the time taken to germinate) of seeds. As with terrestrial birds (Traveset I998), the effects of gut processing by waterfowl vary. In some cases, gut processing increased germinability, but in other cases passage decreased it (Soons et al. 2008; Brochet et al. 20 Iob; García-Álvarez et al. 2015). The rate of germination is usually, but not always, increased by gut passage (Brochet et al. 20Iob; Figuerola et al. 20I0; García-Álvarez et al. 2015). The differences between studies are likely related to plant speciesspecific effects of gut passage on germination capacity.

\section{Which Plants Are Dispersed by Ducks?}

Given the shortage of studies that quantify viable diaspores moved by waterbirds in the field, and given that the great majority of diaspore types have some capacity to survive gut passage, diet studies that identify diaspores are of great interest. Many such studies exist for dabbling ducks, and reanalysis of these datasets sheds light on the variation in dispersal processes over space and time, as well as between specific plant and bird species. The frequency of a given seed type in the upper guts of ducks is a strong predictor of its frequency as a viable seed in faeces (Brochet et al. 2009).

We reviewed 70 studies of the diet of dabbling ducks in Europe and found that seeds of at least 445 plant species of I89 genera and 57 families were reported (table 6.I and supplemental table S6.I at www.press .uchicago.edu/sites/whybirdsmatter/). The species encompass a wide range of families, from Poaceae (grasses), with no obvious adaptations for 
any means of dispersal, to Asteraceae (Compositae), with often complex adaptations for wind dispersal (such as the plume of dandelion seeds).

To find general patterns in the plant species dispersed by dabbling ducks, we analyzed 4I3 of the 444 plant species in Europe, for which quantitative data exist. We analyzed plant traits reflecting species' habitats, seed production, size, and dispersal capacity by wind and water. Species habitat can be estimated using Ellenberg indicator values (Ellenberg et al. I99I), which represent the optimum conditions at which European species occur along an environmental gradient. We looked at species occurrence along the following gradients: nutrient-poor to nutrient-rich (indicated by Ellenberg $N$ values), dry to wet (Ellenberg $F$ ), and shaded to well-lit (Ellenberg $L$ ). Ellenberg values were taken from the PLANTATT database (Hill et al. 2004; extracted 5 December 2006). Species trait data used were seed production (measured as the number of seeds per individual plant, ramet, or tussock), seed size (measured as seed volume, in $\mathrm{mm}^{3}$ ), wind dispersal capacity as approximated by seed terminal velocity (measured as the constant falling rate of a seed in still air, after an initial short phase of acceleration, in $\mathrm{ms}^{-1}$ ) and water dispersal capacity as approximated by seed buoyancy (measured as the percentage of seeds still floating after one week in water). Trait data were taken from the LEDA databse (Kleyer et al. 2008; extracted I3 July 20I0).

Frequency distributions of the Ellenberg values of the species ingested by ducks were compared to those of all plant species for which Ellenberg data are available (fig. 6.3), showing that ducks feed disproportionally on plant species from sites of rich (but not extremely rich) fertility (Ellenberg $N$ values 6-8), wet to inundated sites (Ellenberg $F$ values 8-I2), and habitats on the transition from semishaded to well-lit (Ellenberg $L$ value 7). This analysis shows how plant species from wet, relatively nutrientrich, and relatively open (but not too open) habitats have a greater probability of being dispersed by dabbling ducks.

On the other hand, in terms of numbers of species, fig. 6.3 indicates that most plant species that are present in duck diets, and which therefore are thought to be dispersed by ducks, are not aquatic but rather terrestrial, especially plants of moist soils (Hagy and Kaminski 20I2). Small seeds in terrestrial plants are characteristic of early successional, light-rich environments. Whenever these seeds are washed or blown into wetlands, as during storms, they may be ingested and then dispersed by waterbirds. Wetlands are unsuitable habitat for many plant species whose seeds are taken there by rainfall (Gordon and van der Valk 2003). They may then 
TAB LE 6. I Seeds (oogonia for algae) found in digestive tracts of eight dabbling duck species in Europe (gadwall, garganey, mallard, marbled teal, pintail, shoveler, common teal, and wigeon). Taxonomy is after Flora Europaea (provided online by the Royal Botanic Garden of Edinburgh, accessed in 2013) for plants eaten. Most of the data for the mallard, pintail, and common teal come from the supporting information table provided online for the paper by Brochet et al. (2012a), supplemented by additional references. See table 6.I extended online for more details (www.press .uchicago.edu/sites/whybirdsmatter/).

\section{ALGAE}

Characeae

Chara canescens

Chara sp.

\section{VASCULAR PLANTS}

Alismataceae
Alisma plantago-aquatica
Baldellia ranunculoides
Sagittaria sagittifolia

Amaranthaceae

Amaranthus albus

Amaranthus deflexus

Amaranthus hybridus

Amaranthus retroflexus

Araceae

Calla palustris

Betulaceae

Alnus glutinosa

Alnus incana

Betula pendula

Betula pubescens

Boraginaceae

Myosotis arvensis

Myosotis scorpioides

Callitrichaceae

Callitriche sp.

Caprifoliaceae

Sambucus nigra

Sambucus racemosa

Viburnum lantana

Caryophyllaceae

Arenaria sp.

Cerastium sp.

Lychnis flos-cuculi

Spergula arvensis

Spergularia marina

Spergularia media

Stellaria holostea

Stellaria media

Ceratophyllaceae

Ceratophyllum demersum

Chenopodiaceae

Arthrocnemum fruticosum

Arthrocnemum macrostachyum

Atriplex hastata 
Atriplex hortensis

Atriplex littoralis

Atriplex patula

Atriplex prostrata

Bassia hirsuta

Beta vulgaris

Chenopodium album

Chenopodium ficifolium

Chenopodium glaucum

Chenopodium murale

Chenopodium polyspermum

Chenopodium rubrum

Chenopodium vulvaria

Halimione pedunculata

Halimione portulacoides

Halocnemum strobilaceum

Salicornia europaea

Salsola soda

Suaeda maritima

Suaeda vera

Suaedea corniculata

Compositae

Artemisia sp.

Aster tripolium

Baccharis halimifolia

Bidens cernua

Bidens frondosa

Bidens tripartita

Chamomilla recutita

Cirsium arvense

Cirsium palustre

Cirsium vulgare

Filaginella uliginosa

Helianthus annuus

Hieracium umbellatum

Inula sp.

Senecio aquaticus

Silybum marianum

Soliva sp.

Convolvulaceae

Calystegia sepium

Convolvulus arvensis

Corylaceae

Carpinus betulus

Cruciferae

Brassica napus

Cochlearia sp.

Coronopus squamatus

Lepidium sp.

Nasturtium microphyllum

Nasturtium officinale

continues 


\section{Rapistrum sp.}

Rorippa amphibia

Cyperaceae

Carex acuta

Carex acutiformis

Carex aquatilis

Carex arenaria

Carex bohemica

Carex canescens

Carex chordorrhiza

Carex curta

Carex disticha

Carex divulsa

Carex elata

Carex elongata

Carex extensa

Carex flacca

Carex flava

Carex globularis

Carex hirta

Carex hispida

Carex lasiocarpa

Carex limosa

Carex magellanica

Carex nigra

Carex otrubae

Carex ovalis

Carex pallescens

Carex panicea

Carex paniculata

Carex pilulifera

Carex pseudocyperus

Carex riparia

Carex rostrata

Carex tomentosa

Carex trinervis

Carex vesicaria

Carex vulpina

Carex sp.

Cladium mariscus

Cyperus difformis

Cyperus michelianus

Cyperus serotinus

Eleocharis acicularis

Eleocharis multicaulis

Eleocharis ovata

Eleocharis palustris

Eleocharis uniglumis

Eriophorum vaginatum

Fimbristylis sp.

Schoenus nigricans

Scirpus lacustris

You are reading copyrighted material published by University of Chicago Press. Unauthorized posting, copying, or distributing of this work except as permitted under U.S. copyright law is illegal and injures the author and publisher. 
Scirpus litoralis

Scirpus maritimus

Scirpus mucronatus

Scirpus setaceus

Scirpus sylvaticus

Scirpus triqueter

Elaeagnaceae

Elaeagnus angustifolia

Elatinaceae

Elatine hydropiper

Empetraceae

Empetrum nigrum

Equisetaceae

Equisetum fluviatile

Ericaceae

Calluna vulgaris

Vaccinium myrtillus

Vaccinium uliginosum

Vaccinium vitis-idaea

Fagaceae

Quercus faginea

Quercus robur

Geraniaceae

Geranium dissectum

Geranium robertianum

Guttiferae

Hypericum hirsutum

Haloragaceae

Myriophyllum spicatum

Myriophyllum verticillatum

Hippuridaceae

Hippuris vulgaris

Hydrocharitaceae

Hydrocharis morsus-ranae

Vallisneria spiralis

Iridaceae

Iris pseudacorus

Juncaceae

Cyperus serotinus

Juncus acutiflorus

Juncus articulatus

Juncus compressus

Juncus effusus

Juncus filiformis

Juncus gerardi

Juncus inflexus

Juncus littoralis

Luzula spicata

Juncaginaceae

Triglochin maritima

continues 
Labiatae

Ajuga reptans

Galeopsis speciosa

Galeopsis tetrahit

Lycopus europaeus

Mentha aquatica

Prunella vulgaris

Scutellaria galericulata

Stachys palustris

Leguminosae

Astragalus sp.

Lotus corniculatus

Lotus uliginosus

Medicago arabica

Medicago lupulina

Medicago sativa

Pisum sp.

Trifolium campestre

Trifolium dubium

Trifolium fragiferum

Trifolium pratense

Trifolium repens

Trifolium squamosum

Vicia cracca

Lemnaceae

Lemna gibba

Lythraceae

Lythrum salicaria

Malvaceae

Althaea officinalis

Malva sp.

Marsileaceae

Pilularia sp.

Menyanthaceae

Menyanthes trifoliata

Najadaceae

Najas gracillima

Najas indica

Najas marina

Najas minor

Nymphaeaceae

Nuphar lutea

Nymphaea alba

Nymphoides peltata

Onagraceae

Epilobium hirsutum

Ludwigia peploides

Oxalidaceae

Oxalis sp.

Papaveraceae

Chelidonium majus

Papaver sp.

You are reading copyrighted material published by University of Chicago Press. Unauthorized posting, copying, or distributing of this work except as permitted under U.S. copyright law is illegal and injures the author and publisher. 
Parnassiaceae

Parnassia palustris

Plantaginaceae

Plantago lanceolata

Plantago major

Plantago maritima

Plantago media

Plumbaginaceae

Armeria maritima

Limonium vulgare

Poaceae

Agrostis stolonifera

Alopecurus geniculatus

Alopecurus myosuroides

Alopecurus pratensis

Anthoxanthum odoratum

Apera spica

Arrhenatherum sp.

Avena fatua

Avena sativa

Bromus secalinus

Bromus sterilis

Cynodon dactylon

Digitaria sanguinalis

Echinochloa crus-galli

Eleusine indica

Elymus pungens

Elymus repens

Eragrostis sp.

Festuca arundinacea

Festuca rubra

Glyceria declinata

Glyceria fluitans

Glyceria maxima

Glyceria plicata

Holcus lanatus

Hordeum distichon

Hordeum hystrix

Hordeum marinum

Hordeum secalinum

Hordeum vulgare

Leersia oryzoides

Lolium multiflorum

Lolium perenne

Milium sp.

Oryza sativa

Panicum miliaceum

Parapholis strigosa

Paspalum oaginatum

Paspalum paspalodes

Paspalum vaginatum

continues

You are reading copyrighted material published by University of Chicago Press. Unauthorized posting, copying, or distributing of this work except as permitted under U.S. copyright law is illegal and injures the author and publisher. 
Phalaris arundinacea

Phleum pratense

Phragmites australis

Poa annua

Poa bulbosa

Poa pratensis

Poa trivialis

Polypogon sp.

Puccinellia distans

Puccinellia fasciculata

Puccinellia maritima

Secale cereale

Setaria italica

Setaria pumila

Setaria verticillata

Setaria viridis

Sorghum bicolor

Spartina townsendii

Triticum aestivum

Triticum sp.

Zea mays

Polygonaceae

Fagopyrum esculentum

Fallopia convolvulus

Polygonum amphibium

Polygonum aviculare

Polygonum hydropiper

Polygonum lapathifolium

Polygonum minus

Polygonum mite

Polygonum persicaria

Polygonum viviparum

Rumex acetosa

Rumex acetosella

Rumex aquaticus

Rumex conglomeratus

Rumex crispus

Rumex hydrolapathum

Rumex maritimus

Rumex obtusifolius

Rumex palustris

Rumex pulcher

Pontederiaceae

Heteranthera limosa

Heteranthera reniformis

Potamogetonaceae

Potamogeton acutifolius

Potamogeton berchtoldii

Potamogeton gramineus

Potamogeton lucens

Potamogeton natans

Potamogeton nodosus 
Potamogeton obtusifolius

Potamogeton pectinatus

Potamogeton perfoliatus

Potamogeton polygonifolius

Potamogeton pusillus

Potamogeton trichoides

Primulaceae

Glaux maritima

Lysimachia vulgaris

Ranunculaceae

Ranunculus acris

Ranunculus baudotii

Ranunculus bulbosus

Ranunculus flammula

Ranunculus hederaceus

Ranunculus lingua

Ranunculus repens

Ranunculus sardous

Ranunculus sceleratus

Ranunculus trichophyllus

Thalictrum sp.

Resedaceae

Reseda lutea

Reseda luteola

Rosaceae

Cotoneaster sp.

Crataegus laevigata

Crataegus monogyna

Filipendula ulmaria

Fragaria vesca

Potentilla anserina

Potentilla palustris

Prunus cerasus

Prunus spinosa

Pyrus malus

Rosa canina

Rosa multiflora

Rubus arcticus

Rubus chamaemorus

Rubus fruticosus

Rubus sp.

Sorbus aucuparia

Rubiaceae

Galium aparine

Galium palustre

Galium tricornutum

Ruppiaceae

Ruppia cirrhosa

Ruppia maritima

Salicaceae

Salix sp.

continues 
Scheuchzeriaceae

Scheuchzeria palustris

Scrophulariaceae

Linaria arvensis

Linaria vulgaris

Odontites verna

Rhinanthus minor

Scrophularia auriculata

Scrophularia nodosa

Verbascum sp.

Veronica anagallis-aquatica

Veronica beccabunga

Veronica catenata

Veronica hederifolia

Veronica persica

Solanaceae

Solanum dulcamara

Solanum lycopersicum

Solanum nigrum

Solanum tuberosum

Sparganiaceae

Sparganium angustifolium

Sparganium emersum

Sparganium erectum

Sparganium minimum

Typhaceae

Typha latifolia

Umbelliferae

Anthriscus sylvestris

Cicuta virosa

Falcaria vulgaris

Oenanthe aquatica

Oenanthe fistulosa

Torilis japonica

Urticaceae

Urtica dioica

Valerianaceae Valerianella sp.

Vitaceae

Vitis vinifera

Zannichelliaceae

Zannichellia palustris

Zosteraceae

Zostera angustifolia

Zostera marina

Zostera noltii

You are reading copyrighted material published by University of Chicago Press. Unauthorized posting, copying, or distributing of this work except as permitted under U.S. copyright law is illegal and injures the author and publisher. 

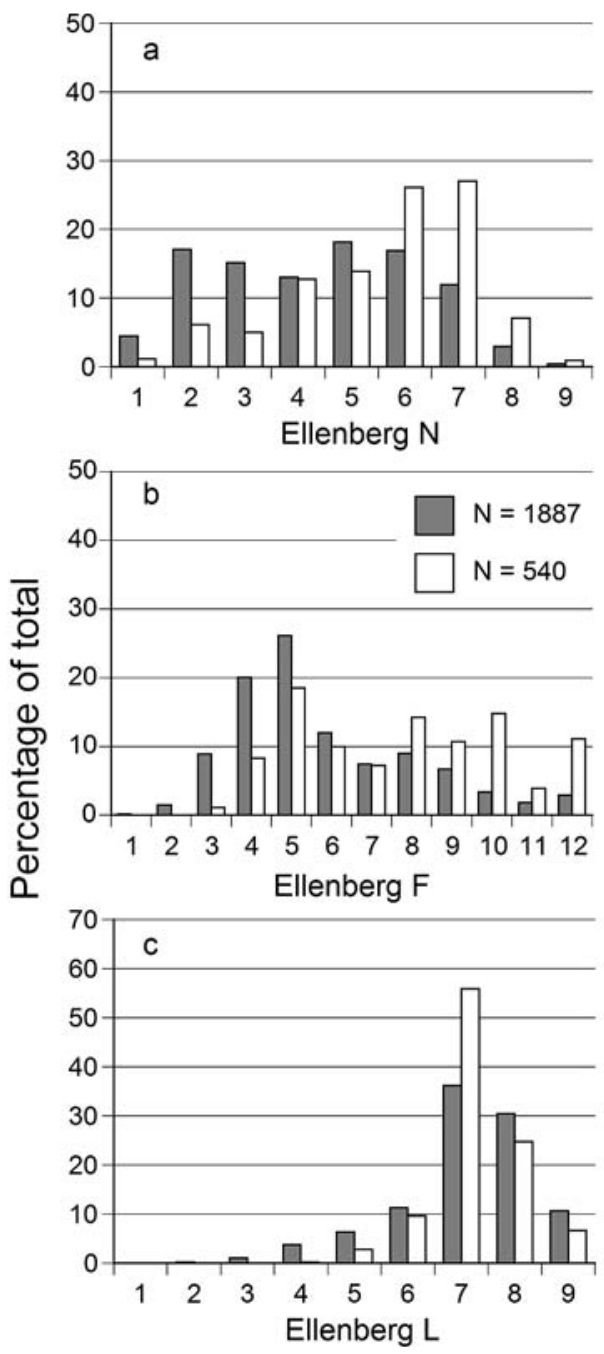

FIGURE 6.3. Analysis of plant species identified from the gut content of Anas dabbling ducks in Europe, in comparison to all European plant species for which Ellenberg values are available, showing that ducks feed disproportionately on plant species at (a) sites of rich fertility (Ellenberg $N$ values 6-8), at (b) wet to inundated (open water) sites (Ellenberg $F$ values 8I2), and at (c) habitats in transition from being semishaded to well lit (Ellenberg L value 7). The gray bars indicate the distribution of Ellenberg values over all plant species; the white bars indicate the distribution for species from duck gut contents. The total number of data points corresponding to dark and light bars for each graph are indicated in the middle panel. 
be returned to terrestrial habitats by waterbirds - for example, by defecation on the shoreline or during flight, or when moved to temporary ponds or flooded grasslands that later dry out.

Analysis of the plant species identified from the gut contents of dabbling ducks in comparison to all plant species for which trait data are available in the LEDA database (fig. 6.4), shows that the ducks feed more or less proportionately on species relative to their seed production and seed buoyancy, but disproportionately more on plant species with seeds of relatively
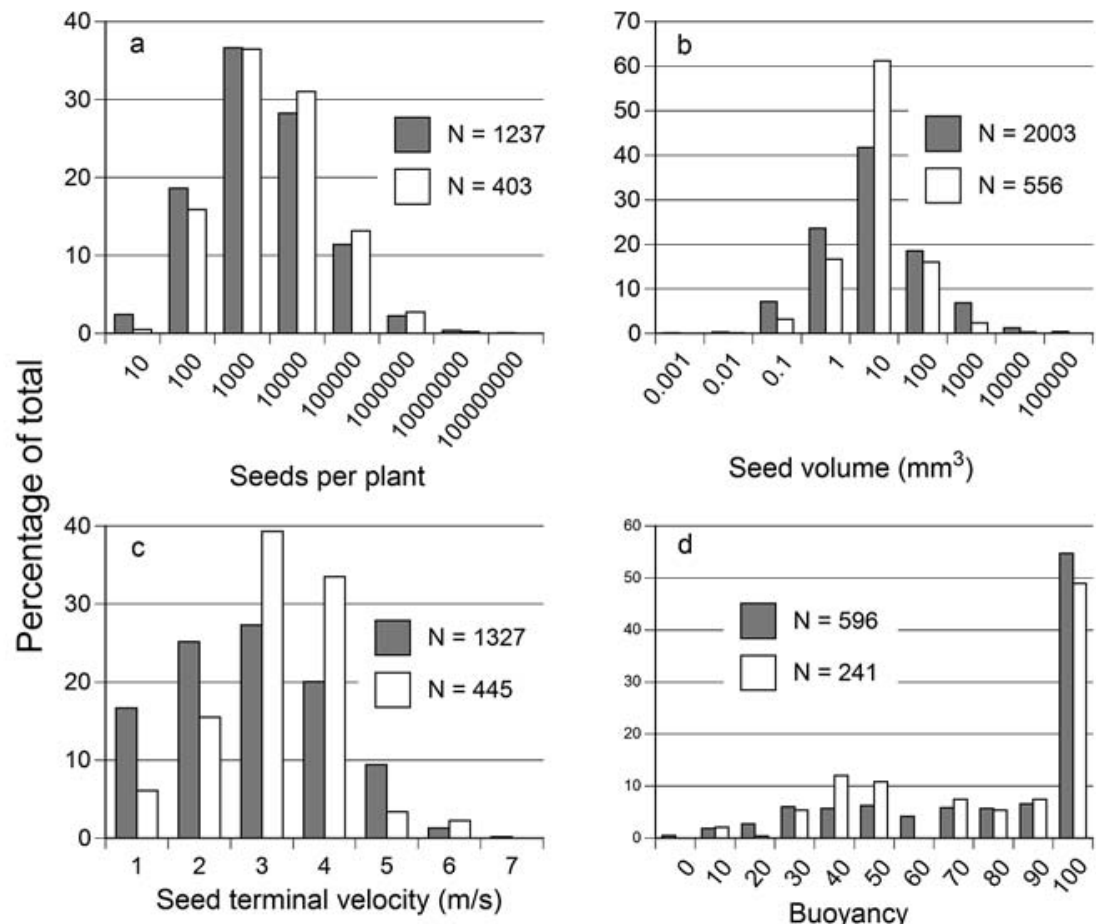

Seed volume $\left(\mathrm{mm}^{3}\right)$

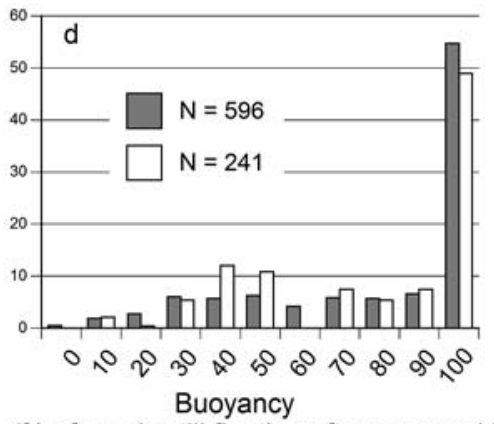

(\% of seeds still floating after one week)

FIGURE 6.4. Analysis of the plant species identified from the gut content of Anas dabbling ducks in Europe, in comparison to all European plant species for which dispersal-related trait data are available, showing that the ducks feed more or less proportionately on species relative to their seed production (a) and seed buoyancy (d), but disproportionately on plant species with seeds of relatively small sizes (b: $\mathrm{I}-\mathrm{IO}_{\mathrm{mm}}{ }^{3}$ ) and high terminal velocities (c: $2-4 \mathrm{~m} / \mathrm{s}$ ). The gray bars indicate the distribution of trait values over all plant species; the white bars indicate the distribution for species from duck gut contents. The total number of data points included in the histograms is indicated in each panel. 
small sizes $\left(\mathrm{I}-\mathrm{IO} \mathrm{mm}^{3}\right)$ and high terminal velocities $\left(2-4 \mathrm{~ms}^{-1}\right)$. Thus, plant species with relatively small seeds, lacking specific adaptations for wind dispersal, have a greater probability of being dispersed by dabbling ducks.

From this analysis it becomes clear that Anas ducks feed on and potentially disperse a very wide range of plant species, and that their role in plant dispersal is very important not only for aquatic species but for moistsoil and terrestrial species within the hydrological catchments of wetlands. This includes many species that on the basis of seed morphology would not be classified by plant ecologists as being primarily dispersed by animals. Such generalizations from measured traits will therefore underestimate a species' potential for dispersal by waterfowl.

Rarefaction analyses (fig. 6.5) show that, in a given study site, ducks are dispersing a high diversity of plant species, and even studies of several hundred duck individuals do not reach an asymptote in taxonomic richness of seeds. How many vascular plant species are being dispersed by ducks in Europe is anybody's guess, and while our review of the literature of dabbling duck diet has identified 445 taxa, the considerable differences between the few localities where detailed studies have been conducted suggests that, on a continental scale, thousands of plant species are being dispersed.
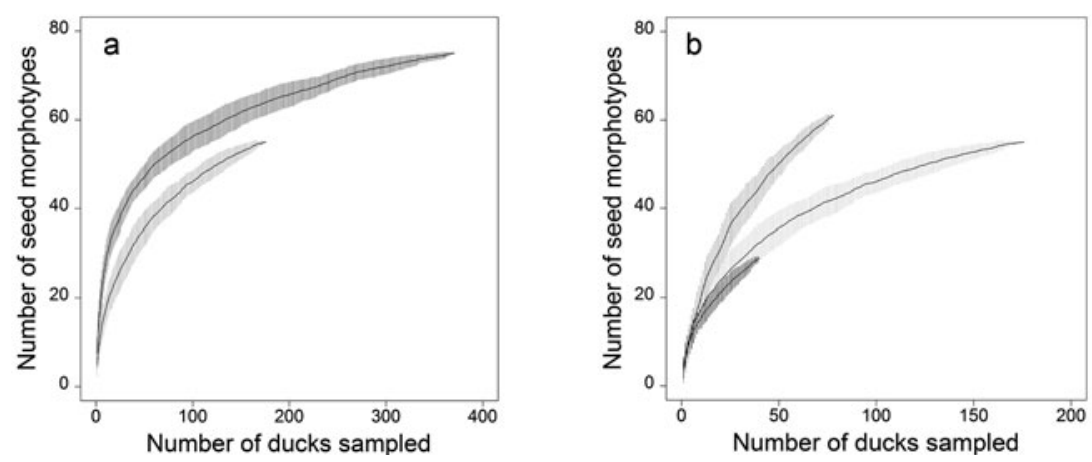

FIGURE 6.5. Rarefaction curves comparing the diversity of seed morphotypes found in the esophagus or gizzard of mallards and green-winged teals, showing means \pm s.e. from random permutations of 50 birds: (a) mallard (light) and green-winged teal (dark), from the Camargue in France; (b) mallard from the Camargue (light), a study in the Netherlands (dark), and the Ebro Delta in Spain (black). Note the change in scale on the $X$ axis. Data reanalyzed from Brochet et al. 20I2a (Camargue), Brochet et al. unpublished (Ebro), and Kleyheeg et al. unpublished (Netherlands). Adjustments were made to the Netherlands data set to ensure comparability (e.g., merging Carex species as in the Camargue study). 


\section{Can Diaspore Morphology Be Used to Predict Which Diaspores Are Dispersed by Waterbirds?}

Much general literature on plant dispersal has been based on the assumption that diaspore morphology provides reliable information as to dispersal means (an idea developed at length by van der Pijl I972). However, waterbirds throw a spanner in the works of such a concept, as there is no way to reliably predict on the basis of morphology - other than (to some extent) size - which diaspores they will disperse, and the list of plant species potentially dispersed by waterbirds would seem to be enormous (perhaps all nonforest species with diaspores with a volume of less than ca. Io $\mathrm{mm}_{3}$ which lie in hydrological catchments frequented by waterbirds). On the basis of small size and lack of fleshy fruits, Tiffney (2004) suggested that Cretaceous angiosperms were predominantly dispersed by abiotic means. Yet waterbird communities, especially shorebirds, were well established by the end of the Early Cretaceous (Lockley et al. I992; Kim et al. 2012), and they were likely to be important diaspore vectors from the very beginning. Tiffney points out that the diaspores of most Cenozoic herbs do not exhibit clear morphological adaptations to vertebrate dispersal (i.e., they lack flesh). However, this cannot be taken as evidence against dispersal by waterbirds. Tiffney argues that biotic dispersal became more widespread and important in the Tertiary than in previous periods, but again by using flesh as the indicator of such dispersal. Likewise, we question Tiffney's assumption that a reduction in diaspore size during climate cooling (during the Tertiary) or with increasing latitude (in modern diaspores) can be taken to indicate a reduced role for biotic dispersal. Janzen (I984) effectively makes the same point by listing many plant genera, classically assumed to disperse by wind or water, which are regularly dispersed by large mammals.

Carlquist (I967) recognized the importance of shorebirds and other waterbirds in the dispersal of plants to oceanic islands, and argued that seed morphology could be used to separate seeds dispersed internally from those dispersed externally. Carlquist and Pauly (1985) later provided experimental support for a link between seed morphology and adhesive capacity for external transport. Nevertheless, many of the plants predicted by Carlquist ( I967) to disperse externally are now known to be readily dispersed internally.

On the basis of a diet review and the intensive study of diaspore dispersal by green-winged teals, Brochet et al. (2009, 20I0a) found that seed 
species dispersed by external transport could not be identified by presence of hooks, barbs, or other structures that might readily be interpreted as adaptations for external attachment. Indeed, there was no clear difference in morphology between seeds found on the outside and the inside of green-winged teals, with much overlap between dispersal modes. In summary, it seems that there are no reliable morphological means, other than seed size, to predict which seed types are dispersed by waterbirds, whether internally or externally. Likewise, the extensive literature on plant dispersal modes that makes predictions based on seed morphology (e.g. Tiffney 2004; Thorsen et al. 2009) seems unreliable in that it overlooks dispersal by waterbirds of seeds that lack the classical predictors of zoochory.

\section{When Are Diaspores Dispersed by Waterbirds and in What Direction?}

Internal transport of diaspores by waterbirds occurs throughout the annual cycle, even though diaspore production itself is often limited seasonally (Kleyheeg 2015). Ducks and other waterbirds frequently ingest diaspores from the seed bank in wetland sediments, where their availability can remain high even at the end of winter (Green et al. 2002). Although migratory ducks in the Northern Hemisphere typically consume more diaspores and fewer invertebrates in winter, they still ingest a variety of diaspores during the breeding season (Green et al. 2002; Rodríguez-Pérez and Green 2006). Few studies examine diets of ducks living in other climatic regions, and some found that seeds dominate the adult diet during the breeding season (Petrie I996; Petrie and Rogers I996). Outside the breeding season, and especially in winter, ducks and many other waterbirds typically undertake regular local movements between sites used for feeding and for resting, and these are often independent waterbodies (Kleyheeg 20I5). Since most preening is carried out at the resting sites, diaspores can be carried on feathers or feet to these latter sites before being removed by preening. Thus, there is likely to be directional dispersal from feeding to resting sites both by endo- and epizoochory (Kleyheeg 20I5). Studies of duck diet on stopover sites during spring and autumn migration in North America confirm that seeds are ingested in abundance on migration by dabbling and diving ducks, and that, while seeds of some plant species are recorded in the diet in greater abundance in autumn, others are found more in spring (Green et al. 2002). 
Figuerola et al. (2002, 2003) conducted a particularly detailed field study of internal transport in Doñana, Spain, Europe's most important wintering site for waterfowl (Rendon et al. 2008). When comparing early winter (November and December, when wintering ducks are still arriving) with late winter (late February, when birds are leaving), they found no consistent difference in rates of seed dispersal, but instead a statistical interaction between season and bird species. For example, numbers of Ruppia maritima seeds were higher in late winter in mallard and northern pintail (Anas acuta) feces, and were lower in late winter for Eurasian coot, but did not change for northern shoveler (A. clypeata). Numbers of Salicornia seeds were higher in early winter for pintail, mallard, and coot, but there was no seasonal difference for shoveler.

Brochet et al. (2010a) found no seasonal variation between early and late winter in the overall rates of diaspore dispersal by green-winged teals in the Camargue when considering intact diaspores found at the end of the lower gut. However, the relative composition of different plant taxa in the diet of green-winged teals did vary during the course of the winter (Brochet et al. 20I2a). Diaspores of some species (e.g., Chara spp.) were more frequently ingested (and hence dispersed) in early winter, while others (e.g., Echinochloa sp.) were more frequent in late winter. Likewise, the diet composition of mallards in the Netherlands varied greatly over the course of autumn and winter (Kleyheeg 20I5).

In conclusion, seasonality influences both the distance and direction of plant dispersal by migratory waterbirds. Plant dispersal occurs yearround, and rates of dispersal may vary among sites and bird species in a manner specific to each plant species. Spring migration is likely to be particularly important for the dispersal of plants responding to climate change, and there is strong potential for long-distance dispersal by waterbirds during this period, even for plants that produce diaspores in summer or autumn.

\section{Specificity or Redundancy: Potential Coevolution between Waterbirds and Diaspores}

Although duck species can differ significantly in the number of diaspores carried for a given plant species, European studies show that, in a given wetland at a given time, different dabbling ducks overlap greatly in the plant species they consume and disperse (fig. 6.6; see also Figuerola et al. 
2003). Although some duck species appear consistently more important as vectors (e.g., green-winged teal and mallard being more important than northern pintail in fig. 6.6), this is largely determined by the relative abundance of the duck species at that site. Green-winged teal and northern shoveler seem consistently to disperse a greater variety of seeds than do mallard on an individual basis (Brochet et al. 2009; see also fig. 6.5a), but the sheer abundance of mallard in some wetlands can make them the dominant vector for any plant species (e.g., in the Ebro delta; fig. 6.6). In Australia, Raulings et al. (20I I) also found high similarity in the plant species dispersed by three duck species by both endo- and epizoochory.

Diaspore size influences the relative importance of different waterfowl species as vectors. Ducks with finer lamellae in their bills (such as the northern shoveler or the green-winged teal) tend to ingest relatively smaller diaspores than do ducks with coarse lamellae (such as mallard; Brochet et al. 20I2b). We reanalyzed data from Brochet et al. 20I2a for teal and mallard, taking the I I diaspore types that were recorded in at least $20 \%$ of individuals of at least one of the duck species. The difference in the mean number of diaspores per bird (in the esophagus or gizzard) between mallard and teal was significantly correlated with diaspore mass, both in early and late winter (Spearman's correlation coefficient $r s=0.57$, 0.56 respectively; $P<$ 0.00I). This pattern largely explains the differences between mallard and teal for individual plant species. For example, Potamogeton pectinatus and $P$. nodosus seeds are much larger than $P$. pusillus seeds, and mallards are particularly important vectors for the first two. Ducks with finer lamellae also tend to disperse a larger number of plant taxa (fig 6.5a and Figuerola et al. 2003).

The high degree of overlap among plant species dispersed by different duck species is also found across different waterbird families, as is shown by comparison of the plants recorded in diets of gulls by Calvino-Cancela (20 I I) with those recorded in ducks by Brochet et al. (2009). Likewise, the diaspores found in the guts of Eurasian coot and gadwall in the Camargue were very similar (Allouche and Tamisier I984). Furthermore, seeds dispersed by terrestrial and aquatic bird species overlap. For example, viable Sonchus oleraceus seeds are dispersed both by shorebirds (Sánchez et al. 2006) and by Eurasian bullfinch Pyrrhula vulgaris (W. E. Collinge in Ridley I930). Five (Plantago lanceolata, Ranunculus repens, Rumex crispus, Polygonum aviculare, Galium aparine) of 17 species recorded to have germinated from songbird droppings by Collinge (in Ridley I930) were listed in duck diet in Europe by Brochet et al. (2009). Similarly, Heleno et al. 


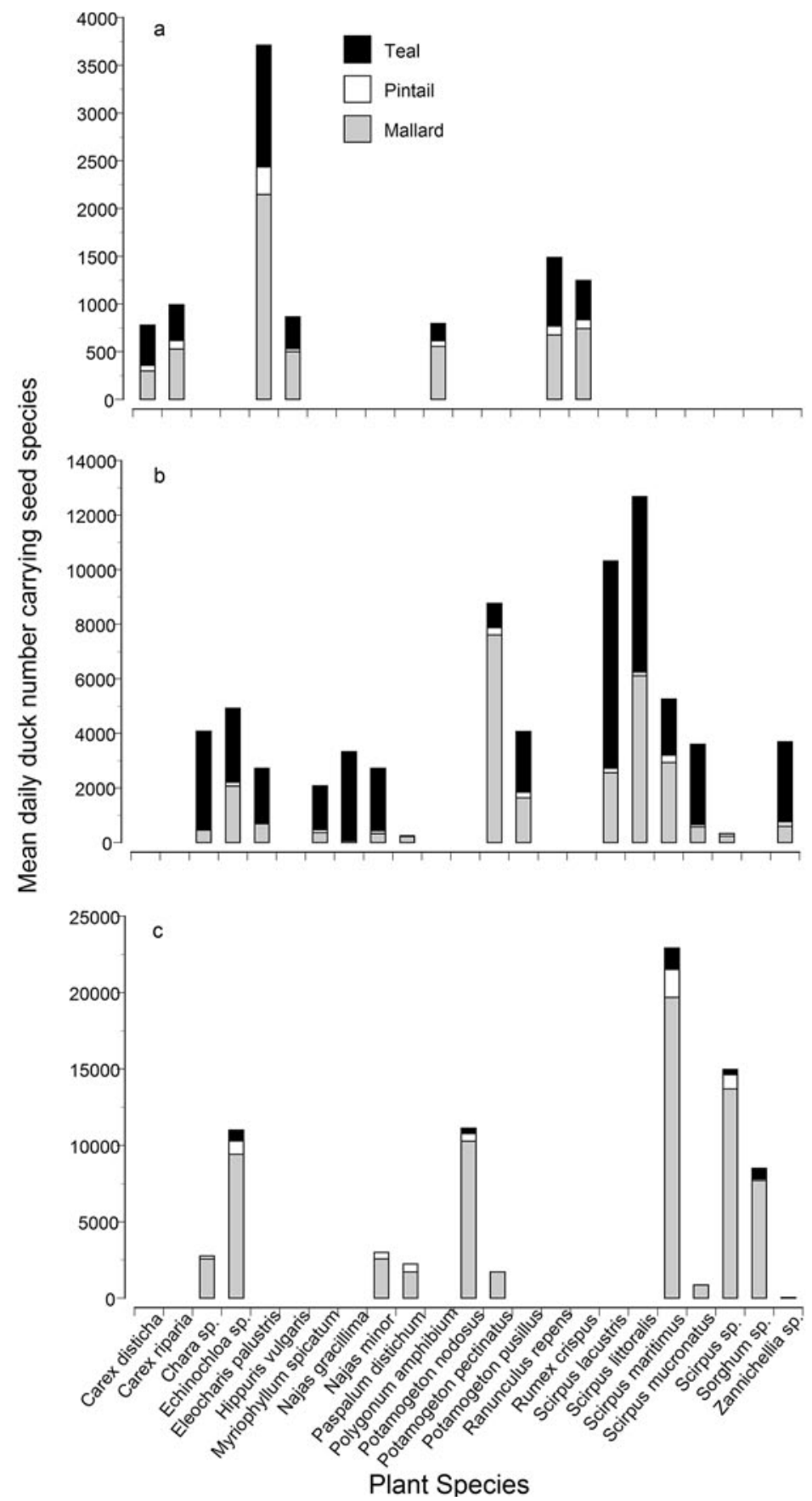

You are reading copyrighted material published by University of Chicago Press. Unauthorized posting, copying, or distributing of this work except as permitted under U.S. copyright law is illegal and injures the author and publisher. 
(20I I) found that passerines dispersed Juncaceae, Cyperaceae and many other seeds without fleshy fruits.

Janzen (I984) envisaged that, prior to human intervention, large migratory mammals such as bovids, proboscideans, glyptodonts, or antilocaprids would have been the most important vectors of diaspores of many aquatic herbs of shallow seasonal marshes, which are now dependent on waterfowl. It is startling how many plant genera associated with pastures are dispersed by large mammals (Janzen I984), and are also frequently dispersed by waterfowl (e.g. Plantago, Medicago, Chenopodium, Carex, Juncus, Ranunculus, Polygonum, Atriplex, Paspalum). Janzen speculated that waterfowl "probably offer only a pale shadow of what once could have been massive seed flow by large herbivores." If he is right, that only increases the importance of the role of waterbirds in conservation of modern ecosystems. Sumoski and Orth (2012) experimentally compared the potential of three fish species, a turtle, and the lesser scaup (Aythya affinis) to vector seeds of the seagrass Zostera marina. The duck was found to have a maximum seed dispersal distance at least I3 times greater than that of any other vector.

Diaspores dispersed by waterbirds are also dispersed by abiotic means, and both may select for diaspore characteristics simultaneously. Diplochory, in which the same individual seed is moved in successive steps, both by birds and by other processes, between the mother plant and germination site (Vander Wall 2004), may be common in waterbird-dispersed plant species. Van der Pijl (I972, I982) recognized that diplochory as a combination of hydro- and endozoochory by waterbirds occurs frequently among Poaceae and Cyperaceae, and as a combination of zoochory and anemochory among Juncaceae and Cyperaceae. Seeds of dry habitats can be transported by waterbirds after being washed or blown into wetlands

FIGURE 6.6. Spatial variation in the dispersal potential of different seeds by different dabbling ducks. The mean number of individuals of green-winged teal (black), mallard (gray), and northern pintail (white) carrying at least one seed of each seed type are presented, on the basis of extrapolating the gut contents by the winter counts for that species, and averaged for the whole winter period. Gut content data taken from (a) Thomas I982, for the Ouse washes in England (1969-72, esophagus plus gizzard), (b) Pirot I98I, for the Camargue in France (I964-8I, esophagus), and (c) Brochet et al. unpublished, for the Ebro delta in Spain (I992-95, oesophagus plus gizzard). Winter counts from the above years were obtained from the British Trust for Ornithology for the Ouse washes, from Tour du Valat for the Camargue, and from Martí and del Moral 2002 for the Ebro Delta. Only seed types present in at least $20 \%$ of individuals of one duck species in one study are included. 
(Cruden I966). The presence of seeds of so many nonaquatic plants in the diet of ducks supports this, as does our review of the buoyancy and terminal velocity of those seeds (fig. 6.4).

In summary, the coevolutionary interaction between most plant species and waterbird species is likely to be very "diffuse," with little evidence for potentially tight coadaptation between a given disperser and a given propagule. Waterbirds disperse many diaspore types that are also dispersed by mammals, terrestrial birds or other animals, and/or by wind or water. Moreover, except in landscapes of low species richness such as oceanic islands, a plant regularly dispersed by one waterbird species is likely to be dispersed by several others, with considerable redundancy between the roles of different vectors.

\section{Are Any Diaspores Adapted for Internal Transport by Waterbirds?}

Contrary to van der Pijl ( I972) and his assumption that waterbirds dispersed "non-adapted diaspores," and despite the diffuse interactions among waterbirds and plants, the relationship between some plants (e.g., some Cyperaceae, pondweeds, and Characeae) and waterbirds seems close enough so that diaspores may be dependent on internal transport by waterbirds, with the possibility of adaptation to these vectors by natural selection. Ridley (I930) proposed that the fleshy red disc in which the stony black achenes of Scleria sumatrensis (Cyperaceae) are supported is an adaptation to visually attract birds, possibly rails. Other authors, such as De Vlaming and Proctor (I968) and Morton and Hogg (I989), suggested that small, dry, hard nutlike seeds are adaptations for dispersal by waterbirds. De Vlaming and Proctor ( I968) suggested that there is a phylogenetic component to such adaptation, with Cyperaceae, for example, being more adapted than Poaceae and Compositae (Asteraceae).

Small diaspore size, often assumed to be an adaptation for abiotic dispersal, especially by wind (Tiffney 2004), also favors waterbird dispersal (fig. 6.4), and these vectors could potentially also exert selection pressure for small size. For example, Charophyte oospores are particularly small, and were the most abundant diaspore in the intestines of green-winged teals (Brochet et al. 20I0a).

Janzen (I984) argued that many herbaceous plants evolved small, hard, numerous seeds with dormancy as adaptations for internal trans- 
port by large mammals, even though these are amongst the "non-adapted diaspores" of van der Pijl (I972). Likewise, such diaspore features could favor, or even be selected for, internal transport by waterbirds (Kleyheeg 20I5). As with seed dispersal by herbivorous mammals (Janzen I984), larger seeds tend to have longer gut retention times in waterbirds, and therefore a greater chance of digestion and mortality. Investment in smaller seeds ensures both greater seed production and an increased probability of dispersal to a suitable microhabitat.

As suggested for seed dispersal by herbivorous mammals (Janzen I984), selection for a seed coat that loses some resistance to germination cues during passage through the waterbird gut depends on whether the potential advantages for rapid germination following dispersal outweigh the potential advantages of delaying germination until some seasonal or successional cue appears in the habitat. In the case of aquatic diaspores, such a cue may include salinity, which itself can vary spatially, seasonally, and annually within a wetland complex. Espinar et al. (2004) found that the influence of gut passage on the germination of Scirpus litoralis seeds depends critically on salinity. Passage increased the germination rate at low salinities, but decreased it at high salinities. This response by the plant is potentially adaptive. When subjected to a similar experiment, seeds of Juncus subulatus survived gut passage, but exhibited no similar response to salinity variation (Espinar et al. 2006).

The proportion of diaspores destroyed during waterbird gut passage varies greatly (Soons et al. 2008; Brochet et al. 20Iob). Nevertheless, even diaspore mortalities of more than $50 \%$ during gut passage are not good evidence that those diaspores are not adapted to dispersal by that vector (Janzen I984). If waterbirds direct diaspores to microhabitats that are suitable for establishment, then high mortalities can be compensated for. Many terrestrial plants have toxic seeds to deter seed predators. The absence of toxic seeds among wetland plants supports the suggestion that these plants are partially adapted to passive dispersal by waterbirds. If, for example, Cyperaceae or pondweed seeds are not adapted for internal transport by waterbirds, then why aren't they toxic so as to avoid seed predation?

However, in the absence of pulp or other tissues that serve to attract animal vectors, it is very hard to establish what selective forces have led to the particular characteristics of diaspores of a given plant species. Not only are diaspores exposed to other modes of biotic and abiotic dispersal, their features are also selected to favor provision of adequate resources for the seedling, and/or survival in the soil or sediment seed bank. 


\section{Is Dispersal Effective? Do Seedlings Get Established after Dispersal?}

Our knowledge about waterbird-mediated diaspore dispersal has rapidly increased in recent years, yet some aspects remain little studied. An essential question yet to be answered is: How effective is diaspore dispersal by waterbirds? Seed dispersal effectiveness can be expressed as "the number of new adult plants produced by the dispersal activities of a disperser" (Schupp I993). This is the result of a series of events (or components of dispersal): ingestion of a certain number of seeds, digestion of a proportion thereof in the digestive tract, excretion in a certain habitat type, seed survival and germination, and plant survival until reproduction. Each of these events is hard to quantify under field conditions (see Herrera et al. I994 for an example from a terrestrial system). To follow the whole cascade for individual seeds is essentially impossible. Although some separate components are now reasonably well studied for waterbird-plant systems, others are not. In particular, research on establishment success following seed dispersal is in its infancy, and has to date focused only on aquatic plants.

Aquatic habitats, compared to terrestrial habitats, provide ecological conditions that are relatively unsuitable for seed germination and seedling establishment (Santamaria 2002). In permanent habitats, clonal populations may persist for many years, even centuries, in the complete absence of seedling establishment. Asexual propagules, such as plant fragments, may disperse more successfully by hydrochory than seeds, owing to their higher establishment capacities. Their passage through the waterbird gut and subsequent dispersal must affect a seed's chances of success, but so far most research has focused simply on documenting the influence of gut passage on germination under laboratory conditions, and specifically on germination rate and germinability.

Competition in aquatic plant populations peaks during the growing season. Seeds might compensate for their poor competitive ability in comparison to established plants or vegetative propagules (which are produced only during the growing season) by their early arrival into a habitat via waterbirds and by early germination, which allows them to reach greater size before competition for light and other resources intensifies. Fennel pondweed ( $P$. pectinatus) seeds grown in mesocosms (in the absence of competition or herbivory) were more likely to germinate early in winter 
when they had passed through a duck gut, although this early start had no effect on the plants' size at the end of the growing season (Figuerola et al. 2005b). Wigeongrass (Ruppia maritima) seeds planted in a marsh frequented by a high density of wintering waterfowl were less likely to produce mature plants when they had passed through the guts of ducks, because earlier germination left them more exposed to herbivory (Figuerola and Green 2004). Gut passage has been shown to accelerate germination in various other plant species, although this effect can be masked by exposure of seeds to cold temperatures prior to experiments (Brochet et al. 20Iob), and may generally be dependent on water salinity (Espinar et al. 2004). In short, much more research is needed on the consequences of seed dispersal by waterbirds and gut passage for the establishment success of plants.

\section{Conclusions and Benefits to People}

Waterbirds are major vectors for a wide variety of plants outside of closed forest habitats, both in wetland and in terrestrial habitats. Tens of thousands of plant species worldwide are likely to benefit from waterbird dispersal for colonization of new habitats, directed dispersal to suitable but hydrologically unconnected sites, gene flow, enhanced germination, and escape from areas of high mortality. Nevertheless, a lack of basic research currently makes it impossible to estimate how many plant species are dispersed by waterbirds and how many waterbird species are effective dispersers for each taxonomic group of plants. Indeed, the limits to which plants can be effectively dispersed by waterbirds are still unclear. Other animals are often alternative vectors for the same plant species, but migratory waterbirds are often highly abundant and are uniquely able to disperse over long distances. Given the recent extinctions and losses of large mammals connecting habitat patches, the role of waterbirds in the dispersal of plants across and between landscapes is likely to have increased-and to increase further in the future. Under the ongoing fragmentation of natural habitats, the ability of waterbirds to fly across barriers is critical. The distances that diaspores are moved by waterbirds remain unclear and little studied, but maxima of hundreds or thousands of kilometers are likely for many migratory species (Viana et al. 2013; Kleyheeg 2015).

Diaspore dispersal by waterbirds is an ecosystem service-specifically, a "supporting service," according to a common classification (MEA 
2005) - that is vital for the maintenance of plant biodiversity and connectivity between populations. Anatidae and other waterbirds play an essential role in the colonization and regeneration of new and restored wetlands by aquatic flora and fauna. Waterbirds play a vital role in maintaining connectivity between aquatic communities in isolated aquatic systems, and thus in maintaining species and genetic diversity (Amezaga et al. 2002). In many cases, plants that are dependent on waterbirds for their dispersal are keystone species - notably pondweeds and other submerged plants. The benefits these plants provide to humans are largely indirect, through control of soil erosion and sedimentation, flood prevention, water purification, carbon sequestration, providing essential habitat for fish, and so on. However, all of these are essential to humans. Direct benefits can also be provided - for example, from the Juncaceae and Cyperaceae that are traditionally used by humans for thatching. There may also be costs, because waterbirds can often be effective at spreading alien plants, including weeds.

In the past, passive dispersal of wetland plants by birds probably enabled the quick recolonization of extensive areas following glacial retreat (Santamaria 2002). Now, and increasingly in the future, plants require waterbirds as vectors if they are to colonize areas that become suitable under climate change. Waterbirds are already shifting their distributions in response to climate change (Visser et al. 2009; Godet et al. 20 I ), though they may track the changes with time lags that potentially have negative consequences for their own population viability. There is already evidence that waterbirds are enabling the colonization of polar regions by new plant species (Klein et al. 2008). It remains to be seen which plants will be able to shift their distributions fast enough via birds to avoid a crash in population range and size. What seems certain is that many species would have much less chance of shifting ranges if it were not for waterbirds. The ecosystem services that waterbirds provide by dispersing plants have an economic value, although no case studies have yet estimated it (Green and Elmberg 20I4). One potential way of valuing part of the dispersal service by waterbirds would be to calculate the replacement costs of manually planting the wetland plant species that become established in and around created or restored wetlands after arriving via birds; those costs alone would be extremely high. In addition, the costs of replacing dikes that are vital in preventing floods, or in containing water in fish ponds, and which are protected from wave erosion by vegetation brought by birds, should be estimated. Recent progress in accounting for ecosystem services provided by migratory species (Semmens 
et al. 20I I) is relevant, since many migratory waterbirds that provide dispersal services cross international borders. For example, ducks dispersing plant diaspores to new habitats in the United States breed largely in Canada. The valuation of such dispersal services by waterbirds is an important avenue for future research (Green and Elmberg 20I4). However, to facilitate such valuation, much basic research is still needed to improve our understanding of which plants are dispersed by waterbirds, and where.

\section{References}

Allouche, L., and Tamisier, A. I984. Feeding convergence of gadwall, coot and other herbivorous waterfowl species wintering in the Camargue: a preliminary approach. Wildfowl 35:135-42.

Amezaga, J. M., Santamaria, L., and Green, A. J. 2002. Biotic wetland connectivity: Supporting a new approach for wetland policy. Acta Oecologica-International Journal of Ecology 23:2 I3-22.

Aoyama, Y., Kawakami, K., and Chiba, S. 20I2. Seabirds as adhesive seed dispersers of alien and native plants in the oceanic Ogasawara Islands, Japan. Biodiversity and Conservation 21:2787-280I.

Arber, A. I920. Water plants: A study of aquatic angiosperms. Cambridge: Cambridge University Press.

Bell, D. M. 2000. The ecology of coexisting Eleocharis species. PhD thesis, University of New England, Armidale.

Beltzer, A. H., Sabattini, R. A., and Marta, M. C. I99I. Ecología alimentaria de la polla de agua negra Gallinula chloropus galeata (Aves: Rallidae) en un ambiente lenítico del río Paraná medio, Argentina. Ornitología Neotropical 2:29-36.

Black, J. M., Prop, J., Hunter, J. M., Woog, F., Marshall, A. P., and Bowler, J. M. I994. Foraging behaviour and energetics of the Hawaiian Goose Branta sandvicensis. Wildfowl 45:65-I09.

Brochet, A. L., Guillemain, M., Fritz, H., Gauthier-Clerc, M., and Green, A. J. 2009. The role of migratory ducks in the long-distance dispersal of native plants and the spread of exotic plants in Europe. Ecography 32:919-28.

- 20roa. Plant dispersal by teal (Anas crecca) in the Camargue: Duck guts are more important than their feet. Freshwater Biology 55:I262-73.

Brochet, A. L., Guillemain, M., Gauthier-Clerc, M., Fritz, H., and Green, A. J. 20Iob. Endozoochory of Mediterranean aquatic plant seeds by teal after a period of desiccation: Determinants of seed survival and influence of retention time on germinability and viability. Aquatic Botany 93:99-Io6.

Brochet, A. L., Dessborn, L., Legagneux, P., Elmberg, J., Gauthier-Clerc, M., Fritz, H., and Guillemain, M. . 20I2b. Is diet segregation between dabbling ducks due to food partitioning? A review of seasonal patterns in the Western Palearctic. Journal of Zoology 286:I7 I-78. 
Brochet, A. L., Mouronval, J. B., Aubry, P., Gauthier-Clerc, M., Green, A. J., Fritz, H. and Guillemain, M. 20I2a. Diet and feeding habitats of Camargue dabbling ducks: What has changed since the I96os? Waterbirds 35:555-76.

Bruun, H. H., Lundgren, R., and Philipp, M. 2008. Enhancement of local species richness in tundra by seed dispersal through guts of muskox and barnacle goose. Oecologia I55:I0I-IO.

Burger, A. E. 2005. Dispersal and germination of seeds of Pisonia grandis, an IndoPacific tropical tree associated with insular seabird colonies. Journal of Tropical Ecology 2I:263-7I.

Calvino-Cancela, M. 20I I. Gulls (Laridae) as frugivores and seed dispersers. Plant Ecology 2I2:I I49-57.

Carlquist, S. 1967. Biota of Long-Distance Dispersal: V. Plant Dispersal to Pacific Islands. Bulletin of the Torrey Botanical Club 94:I29-62.

Carlquist, S., and Pauly, Q. I985. Experimental studies on epizoochorous dispersal in Californian plants. Aliso I I:167-77.

Chang, E. R., Zozaya, E. L., Kuijper, D. P. J., and Bakker, J. P. 2005. Seed dispersal by small herbivores and tidal water: Are they important filters in the assembly of salt-marsh communities? Functional Ecology i9:665-73.

Charalambidou, I., and Santamaría, L. 2002. Waterbirds as endozoochorous dispersers of aquatic organisms: A review of experimental evidence. Acta Oecologica $23: 165-76$.

. 2005. Field evidence for the potential of waterbirds as dispersers of aquatic organisms. Wetlands 25:252-58.

Charalambidou, I., Santamaria, L., Jansen, C., and Nolet, B. A. 2005. Digestive plasticity in Mallard ducks modulates dispersal probabilities of aquatic plants and crustaceans. Functional Ecology I9:5 I3-I9.

Choi, C.-Y., Nam, H.-Y., and Chae H.-Y. 20ro. Exotic seeds on the feathers of migratory birds on a stopover island in Korea. Journal of Ecology and Field Biology 33:19-22.

Cook, C. D. K. I990. Seed dispersal of Nymphoides peltata (S.G. Gmelin) O. Kuntze (Menyanthaceae). Aquatic Botany 37:325-40.

Corlett, R. T. 1998. Frugivory and seed dispersal by vertebrates in the Oriental (Indomalayan) Region. Biological Reviews of the Cambridge Philosophical Society 73:4I3-48.

Coughlan, N. E., Kelly, T. C., and Jansen, M. A. K. . 2015. Mallard duck (Anas platyrhynchos)-mediated dispersal of Lemnaceae: A contributing factor in the spread of invasive Lemna minuta? Plant Biology I7:I08-4.

Cruden, R. W. I966. Birds as agents of long-distance dispersal for disjunct plant groups of temperate Western Hemisphere. Evolution 20:5I7-32.

Darwin, C. I859. The Origin of Species by Means of Natural Selection. Ist ed. London: John Murray.

I872. The Origin of Species by Means of Natural Selection. 6th ed. London: John Murray. 
Davidson, N. C. 20I4. How much wetland has the world lost? Long-term and recent trends in global wetland area. Marine and Freshwater Research 65: 934-4I.

De Vlaming, V., and Proctor, V. W. I968. Dispersal of aquatic organisms: Viability of seeds recovered from the droppings of captive killdeer and mallard ducks. American Journal of Botany 55:20-26.

Dehorter, O., and Guillemain, M. 2008. Global diversity of freshwater birds (Aves). Hydrobiologia 595:6I9-26.

Downing, J. A. 2009. Plenary lecture global limnology: Up-scaling aquatic services and processes to planet Earth. Verh Internat Verein Limnol 30:I I 49-66.

Ellenberg, H., Weber, H. E., Düll, R., Wirth, V., Werner, W., and Paulissen, D. I99I. Zeigerwerte von Pflanzen in Mitteleuropa. Scripta Geobotanica I8:I-248.

Espinar, J. L., Garcia, L. V., Figuerola, J., Green A. J., and Clemente, L. 2004. Helophyte germination in a Mediterranean salt marsh: Gut-passage by ducks changes seed response to salinity. Journal of Vegetation Science I5:3 I5-22.

- 2006. Effects of salinity and ingestion by ducks on germination patterns of Juncus subulatus seeds. Journal of Arid Environments 66:376-83.

Falla, R. A. I960. Oceanic birds as dispersal agents. Proceedings of the Royal Society London Series B I52:655-59.

Figuerola, J., Charalambidou, I., Santamaria, L., and Green, A. J. 20I0. Internal dispersal of seeds by waterfowl: Effect of seed size on gut passage time and germination patterns. Naturwissenschaften 97:555-65.

Figuerola, J., and Green, A. J. 2002a. Dispersal of aquatic organisms by waterbirds: A review of past research and priorities for future studies. Freshwater Biology 47:483-94.

- 2002b. How frequent is external transport of seeds and invertebrate eggs by waterbirds? A study in Donana, SW Spain. Archiv Fur Hydrobiologie I55: $557-65$.

-2004. Effects of seed ingestion and herbivory by waterfowl on seedling establishment: A field experiment with wigeongrass Ruppia maritima in Donana, south-west Spain. Plant Ecology 173:33-38.

Figuerola, J., Green, A. J., and Santamaria, L. 2002. Comparative dispersal effectiveness of wigeongrass seeds by waterfowl wintering in south-west Spain: Quantitative and qualitative aspects. Journal of Ecology 90:989-I00I.

- 2003. Passive internal transport of aquatic organisms by waterfowl in Doñana, south-west Spain. Global Ecology and Biogeography I2:427-36.

Figuerola, J., Mateo, R., Green, A. J., Mondain-Monval, J. Y., Lefranc, H., and Mentaberre, G. 2005a. Grit selection in waterfowl and how it determines exposure to ingested lead shot in Mediterranean wetlands. Environmental Conservation 32:226-34.

Figuerola, J., Santamaria, L., Green, A. J., Luque, I., Alvarez, R., and Charalambidou, I. 2005b. Endozoochorous dispersal of aquatic plants: Does seed gut passage affect plant performance? American Journal of Botany 92:696-99. 
Fuentes, C., Green, A. J., Orr, J., and Olafsson, J. S. 2005. Seasonal variation in species composition and larval size of the benthic chironomid communities in brackish wetlands in southern Alicante, Spain. Wetlands 25:289-96.

García-Álvarez, A., van Leeuwen, C. H. A., Luque, C. J., Hussner, A., Vélez-Martín, A., Pérez-Vázquez, A., Green, A. J., and Castellanos, E. M. 20I5. Internal transport of alien and native plants by geese and ducks: An experimental study. Freshwater Biology 60:13i6-29.

Gill, R. E., Tibbitts, T. L., Douglas, D. C., Handel, C. M., Mulcahy, D. M., Gottschalck, J. C., Warnock, N., et al. 2009. Extreme endurance flights by landbirds crossing the Pacific Ocean: Ecological corridor rather than barrier? Proceedings of the Royal Society B-Biological Sciences 276:447-58.

Godet, L., Jaffre, M., and Devictor, V. 20II. Waders in winter: Long-term changes of migratory bird assemblages facing climate change. Biology Letters 7:7I4-I7.

Gordon, E., and van der Valk, A. G. 2003. Secondary seed dispersal in Montrichardia arborescens (L.) schott-dominated wetlands in Laguna Grande, Venezuela. Plant Ecology I68:I77-90.

Green, A. J., and Elmberg, J. 20I4. Ecosystem services provided by waterbirds. Biological Reviews 89:105-22.

Green, A. J., Figuerola, J., and Sanchez, M. I. 2002. Implications of waterbird ecology for the dispersal of aquatic organisms. Acta Oecologica-International Journal of Ecology 23:177-89.

Green, A. J., Jenkins, K. M., Bell, D., Morris, P. J., and Kingsford, R. T. 2008. The potential role of waterbirds in dispersing invertebrates and plants in arid Australia. Freshwater Biology 53:380-92.

Guppy, H. B. 1906. Observations of a Naturalist in the Pacific between I896 and I899. Vol. 2. Plant-dispersal. London: Macmillan.

Gurd, D. B. 2006. Filter-feeding dabbling ducks (Anas spp.) can actively select particles by size. Zoology I09:I20-26.

Hagy, H. M., and Kaminski, R. M. . 20I2. Apparent seed use by ducks in moistsoil wetlands of the Mississippi alluvial valley. Journal of Wildlife Management 76:I053-I06I.

Halse, S. A. I984. Diet, body condition, and gut size of Egyptian geese. Journal of Wildlife Management 48:569-73.

- I985. Diet and size of the digestive organs of spur-winged geese. Wildfowl 36:129-34.

Heleno, R. H., Ross, G., Everard A., Memmott J., and Ramos, J. A. 20I I. The role of avian "seed predators" as seed dispersers. Ibis I53:199-203.

Herrera, C. M., Jordano, P., Lopez Soria, L., Amat, J. A. I994 Recruitment of a mast-fruiting, bird-dispersed tree: Bridging frugivore activity and seedling establishment. Ecological Monographs 64:3 I5-44.

Heslop-Harrison, Y. 1955. Nuphar Sm. Journal of Ecology 43:342-64. 
Hill, M. O., Preston, C. D., and Roy, D. B. 2004. PLANTATT: Attributes of British and Irish plants: Status, size, life history, geography and habitats. Huntington, U.K.: Centre for Ecology and Hydrology

Holmboe, J. I90o. Notizen über die endozische Samenverbreitung der Vögel. Nyt magazin for naturuidenskaberne 38.

Howe, H. F., and Smallwood, J. I982. Ecology of seed dispersal. Annual Review of Ecology and Systematics I3:20 I-28.

Isaac-Renton, M., Bennett, J. R., Best, R. J., and Arcese, P. 20I0. Effects of introduced Canada geese (Branta canadensis) on native plant communities of the Southern Gulf Islands, British Columbia. Ecoscience I7:394-99.

James, H. F., and Burney, D. A. . I997. The diet and ecology of Hawaii's extinct flightless waterfowl: Evidence from coprolites. Biological Journal of the Linnean Society 62:279-97.

Janzen, D. H. I984. Dispersal of small seeds by big herbivores: Foliage is the fruit. American Naturalist I23:338-53.

Kear, J. I990. Man and Wildfowl. London: T \& A.D. Poyser.

Kim, J. Y., Lockley, M. G., Seo, S. J., Kim, K. S., Kim, S. H., and Baek, K. S. 2012. A paradise of mesozoic birds: The world's richest and most diverse cretaceous bird track assemblage from the Early Cretaceous Haman formation of the Gajin Tracksite, Jinju, Korea. Ichnos-an International Journal for Plant and Animal Traces I9:28-42.

Klein, D. R., Bruun, H. H., Lundgren, R., and Philipp, M. 2008. Climate change influences on species interrelationships and distributions in high-Arctic Greenland. Advances in Ecological Research 40:8I-I00.

Kleyer, M., Bekker R. M., Knevel, I. C., Bakker, J. P., Thompson, K., Sonnenschein, M., Poschlod, P., et al. 2008. The LEDA Traitbase: A database of lifehistory traits of the Northwest European flora. Journal of Ecology 96:1 266-74.

Kleyheeg, E. 2015. Seed dispersal by a generalist duck: Ingestion, digestion and transportation by mallards (Anas platyrhynchos). PhD thesis, Utrecht University, the Netherlands.

Kleyheeg, E., van Leeuwen, C. H., Morison, M. A., Nolet, B. A., and Soons, M. B. 2015. Bird-mediated seed dispersal: Reduced digestive efficiency in active birds modulates the dispersal capacity of plant seeds. Oikos. I24:899-907.

Lewis, L. R., Behling, E., Gousse, H., Qian, E., Elphick, C. S., Lamarre, J. F., Bety, J., Liebezeit, J., Rozzi, R., and Goffinet, B. 20I4. First evidence of bryophyte diaspores in the plumage of transequatorial migrant birds. PeerJ 2:e424.

Lockley, M. G., Lim, J. D., Kim, J. Y., Kim, K. S., Huh, M., and Hwang, K. G. 2012. Tracking Korea's early birds: A review of cretaceous avian ichnology and its implications for evolution and behavior. Ichnos I9:17-27.

Lougheed, V. L., McIntosh, M. D., Parker, C. A., and Stevenson, R. J. 2008. Wetland degradation leads to homogenization of the biota at local and landscape scales. Freshwater Biology 53:2402-13. 
Magnússon, B., Magnússon, S. H., and Fridriksson, S. 2009. Developments in plant colonization and succession on Surtsey during 1999-2008. Surtsey Research I2: $57-76$.

Malone, C. R. 1966. Regurgitation of food by mallard ducks. Wilson Bulletin 78:227-28.

Marchant, S., and Higgins, P. J. 1990. Handbook of Australian, New Zealand and Antarctic Birds, vol. I. Melbourne: OUP.

Martí, R., and del Moral, J. C. 2002. La invernada de aves acuáticas en España. Madrid: Organismo Autónomo Parques Nacionales, Ministerio de Medio Ambiente.

Maximilian, Prince of Wied-Neuwied. I820: Travels in Brazil in the Years I815, I8I6, I8I7. London: Henry Colburn \& Co.

Milcu, A., Schumacher, J., and Scheu, S. 2006. Earthworms (Lumbricus terrestris) affect plant seedling recruitment and microhabitat heterogeneity. Functional Ecology 20:26I-68.

Millennium Ecosystem Assessment (MEA). 2005. Ecosystems and Human WellBeing: Wetlands and Water. Washington: World Resources Institute.

Montalti, D., Arambarri, A. M., Soave, G. E., Darrieu, C. A., and Camperi, A. R. 2003. Seeds in the diet of the white-rumped sandpiper in Argentina. Waterbirds 26: $666-68$.

Morton, J. K., and Hogg, E. H. I989. Biogeography of island floras in the Great Lakes. 2. Plant dispersal. Canadian Journal of Botany / Revue Canadienne de Botanique 67: $1803^{-20 .}$

Mouronval, J. B., Guillemain, M., Canny, A., and Poirier, F. 2007. Diet of nonbreeding wildfowl Anatidae and Coot Fulica atra on the Perthois gravel pits, northeast France. Wildfowl 57:68-97.

Mueller, H. I999. Common snipe, Gallinago gallinago. In The Birds of North America, A. Poole, and F. Gill, ed., No. 4I7. Philadelphia: The Academy of Natural Sciences and Washington, D.C.: The American Ornithologists' Union.

Nathan, R., Perry, G., Cronin, J. T., Strand, A. E., and Cain, M. L. 2003. Methods for estimating long-distance dispersal. Oikos I03:26I-73.

Neff, K. P., and A. H. Baldwin. 2005. Seed dispersal into wetlands: Techniques and results for a restored tidal freshwater marsh. Wetlands 25:392-404.

Petrie, S. A. 1996. Red-billed teal foods in semiarid South Africa: A NorthTemperate contrast. Journal of Wildlife Management 60:874-8I.

Petrie, S. A., and Rogers, K. H. I996. Foods consumed by breeding white-faced whistling ducks (Dendrocygna viduata) on the Nyl river floodplain, South Africa. Gibier Faune Sauvage I3:755-7I.

Pirot, J. Y. I98I. Partage alimentaire et spatial des zones humides camarguaises par cinq espèces de canards en hivernage et en transit. $\mathrm{PhD}$ thesis, Pierre et Marie Curie University, Paris.

Proctor, V. W. I968. Long-distance dispersal of seeds by retention in digestive tract of birds. Science I60:32 I-22. 
Purves, D. W., and Dushoff, J. 2005. Directed seed dispersal and metapopulation response to habitat loss and disturbance: Application to Eichhornia paniculata. Journal of Ecology 93:658-69.

Raulings, E., Morris, K., Thompson, R., and Mac Nally, R. 20I I. Do birds of a feather disperse plants together? Freshwater Biology 56:1390-I402.

Rendon, M. A., Green, A. J., Aquilera, E., and Almaraz, P. 2008. Status, distribution and long-term changes in the waterbird community wintering in Donana, south-west Spain. Biological Conservation I4I:I37I-88.

Ridley, H. N. I930. The Dispersal of Plants throughout the World. Ashford, Kent, UK: L. Reeve \& Co.

Rodríguez, R., and Hiraldo, F. 1975. Régimen alimenticio del Calamón (Porphyrio porphyrio) en las marismas del Guadalquivir. Doñana Acta Vertebrata 2:20I-I3.

Rodriguez, A., Rodriguez, B., Rumeu, B., and Nogales, M. 2007. Seasonal diet of the grey heron Ardea cinerea on an oceanic island (Tenerife, Canary Islands): Indirect interaction with wild seed plants. Acta Ornithologica 42:77-87.

Rodríguez-Pérez, H., and Green, A. J. 2006. Waterbird impacts on widgeongrass Ruppia maritima in a Mediterranean wetland: Comparing bird groups and seasonal effects. Oikos I I2:525-34.

Sánchez, M. I., Green, A. J., and Castellanos, E. M. 2006. Internal transport of seeds by migratory waders in the Odiel marshes, south-west Spain: Consequences for long-distance dispersal. Journal of Avian Biology 37:20I-6.

Santiago-Quesada, F., J. A. Masero, N. Albano, A. Villegas, and J. M. SanchezGuzman. 2009. Sex differences in digestive traits in sexually size-dimorphic birds: Insights from an assimilation efficiency experiment on black-tailed godwit. Comparative Biochemistry and Physiology a. Molecular \& Integrative Physiology $\mathrm{I} 52: 565-68$.

Sarneel, J. M., Beltman, B., Buijze, A., Groen, R., and Soons, M. B. 2013. The role of wind in the dispersal of floating seeds in slow flowing or stagnant water bodies. Journal of Vegetation Science 25:262-74.

Schupp, E. W. I993. Quantity, quality and the effectiveness of seed dispersal by animals. Vegetation I07/I08:I5-29.

Şekercioğlu, Ç. H. 2006. Increasing awareness of avian ecological function. Trends in Ecology \& Evolution 2I:464-7I.

Semmens, D. J., Diffendorfer, J. E., Lopez-Hoffman, L., and Shapiro, C. D. 20 I I. Accounting for the ecosystem services of migratory species: Quantifying migration support and spatial subsidies. Ecological Economics 70:2236-42.

Sibly, R. M. I98I. Strategies of digestion and defecation. In Physiological Ecology: An Evolutionary Approach to Resource Use, ed. C. R. Townsend and P. Calow, I09-39. Sunderland, MA: Sinauer.

Smits, A. J. M., Vanruremonde, R., and Vandervelde, G. I989. Seed dispersal of 3 nymphaeid macrophytes. Aquatic Botany 35:167-80. 
Soltis, D. E., Bell, C. D., Kim, S., and Soltis, P. S. 2008. Origin and early evolution of angiosperms. Year in Evolutionary Biology 2008 I I33:3-25.

Soomers, H., Karssenberg, D., Soons, M. B., Verweij, P., Verhoeven, J. T. A., and Wassen, M. J. 20I3. Wind and water dispersal of wetland plants across fragmented landscapes. Ecosystems i6:434-5I.

Soons, M.B. 2006. Wind dispersal in freshwater wetlands: Knowledge for conservation and restoration. Applied Vegetation Science 9:27I-78.

Soons, M. B., van der Vlugt, C., van Lith, B., Heil, G. W., and Klaassen, M. 2008. Small seed size increases the potential for dispersal of wetland plants by ducks. Journal of Ecology 96:619-27.

Sumoski, S. E., and Orth, R. J. . 20I2. Biotic dispersal in eelgrass Zostera marina. Marine Ecology Progress Series 47I:I-IO.

Summers, R. W., Stansfield, J., Perry, S., Atkins, C., and Bishop, J. I993. Utilization, diet and diet selection by brent geese Branta bernicla bernicla on saltmarshes in Norfolk. Journal of Zoology 23 I:249-73.

Tárano, Z., Stahl, S., and Ojasti, J. 1995. Feeding ecology of the purple gallinule (Porphyrula martinica) in the central Llanos of Venezuela. Ecotropicos 8:53-6I.

Taylor, B. W. 1954. An example of long-distance dispersal. Ecology 35:569-72.

Thomas, G. J. I982. Autumn and winter feeding ecology of waterfowl at the Ouse Washes, England. Journal of Zoology I97:I3 I-72.

Thorsen, M. J., Dickinson, K. J. M., and Seddon, P. J. 2009. Seed dispersal systems in the New Zealand flora. Perspectives in Plant Ecology Evolution and Systematics I I:285-309.

Tiffney, B. H. 2004. Vertebrate dispersal of seed plants through time. Annual Review of Ecology Evolution and Systematics 35:I-29.

Traveset, A. I998. Effect of seed passage through vertebrate frugivores' guts on germination: A review. Perspectives in Plant Ecology Evolution and Systematics I/2:I5I-90.

Tréca, B. I98I. Régime alimentaire du Dendrocygne veuf (Dendrocygna viduata) dans le delta du Sénégal. L'Oiseau et la Revue Française d'Ornithologie 5I:219-38.

United States Fish and Wildlife Service (USFWS). 20I2. Waterfowl Population Status, 20I2. Washington: US Department of the Interior.

Van der Pijl, L. I972. Principles of Dispersal in Higher Plants. 2nd edition. Berlin: Springer-Verlag.

- 1982. Principles of Dispersal in Higher Plants. 3rd edition. Berlin: Springer-Verlag.

Van Leeuwen, C. H. A., Van der Velde, G., Van Groenendael, J. M., and Klaassen, M. 20I2. Gut travellers: Internal dispersal of aquatic organisms by waterfowl. Journal of Biogeography 39:203 I-40.

Vander Wall, S. B., and Longland, W. S. 2004. Diplochory: Are two seed dispersers better than one? Trends in Ecology \& Evolution I9: I55-6I. 
Viain, A., F. Corre, P. Delaporte, E.Joyeux, and P. Bocher. 20I I. Numbers, diet and feeding methods of common shelduck Tadorna tadorna wintering in the estuarine bays of Aiguillon and Marennes-Oléron, western France. Wildfowl 6I:I2I-4I.

Viana, D. S., Santamaria, L., Michot, T. C., and Figuerola, J. 20I3. Migratory strategies of waterbirds shape the continental-scale dispersal of aquatic organisms. Ecography 36:430-38.

Visser, M. E., Perdeck, A. C., van Balen, J. H., and Both, C. 2009. Climate change leads to decreasing bird migration distances. Global Change Biology I5: $1859-65$.

Vivian-Smith, G., and Stiles, E. W. I994. Dispersal of salt marsh seeds on the feet and feathers of waterfowl. Wetlands I4:3 I6-I9.

Weddell, H. A. I849. Observations sur une espece nouvelle du genre Wolffia (Lemnacees). Annales des Sciences Naturelles (Botanique) I2:I55-73.

Wetlands International. 20I2. Waterbird Population Estimates, Fifth Edition: Summary Report. Wageningen, the Netherlands: Wetlands International.

Willson, M. F., Traveset, A., and Sabag, C. I997. Geese as frugivores and probable seed-dispersal mutualists. Journal of Field Ornithology 68: I44-46.

Wongsriphuek, C., Dugger, B. D., and Bartuszevige, A. M. 2008. Dispersal of wetland plant seeds by mallards: Influence of gut passage on recovery, retention, and germination. Wetlands 28:290-99.

Wormworth, J., Şekercioğlu, Ç. H. 2011. Winged Sentinels: Birds and Climate Change. Cambridge University Press, New York. 